Portland State University

PDXScholar

\title{
The Voices of Special Educators: How Do Special Educators Teach English Language Learners Who are Receiving Special Education Services?
}

\author{
Elizabeth Ann DuBois \\ Portland State University
}

Follow this and additional works at: https://pdxscholar.library.pdx.edu/open_access_etds

Part of the Educational Leadership Commons, and the Special Education and Teaching Commons Let us know how access to this document benefits you.

\section{Recommended Citation}

DuBois, Elizabeth Ann, "The Voices of Special Educators: How Do Special Educators Teach English Language Learners Who are Receiving Special Education Services?" (2017). Dissertations and Theses. Paper 3638.

https://doi.org/10.15760/etd.5522

This Dissertation is brought to you for free and open access. It has been accepted for inclusion in Dissertations and Theses by an authorized administrator of PDXScholar. Please contact us if we can make this document more accessible: pdxscholar@pdx.edu. 
The Voices' of Special Educators:

How Do Special Educators Teach English Language Learners

Who are Receiving Special Education Services?

by

Elizabeth Ann DuBois

A dissertation submitted in partial fulfillment of the requirements for the degree of

Doctor of Education

in

Educational Leadership: Special and Counselor Education

\begin{abstract}
Dissertation Committee:
Ann Fullerton, Chair

Dannelle D. Stevens

Joanne E. Cooper

Lynn M. Santelmann
\end{abstract}

Portland State University

2017 


\section{(C) 2017 Elizabeth Ann DuBois}




\begin{abstract}
Disproportionality in special education has been examined from various perspectives over a 50-year period. English Language Learner (ELL) students have been included in the discussion among researchers in the past two decades as a disproportionate number of ELL students are referred to special education. Though the problem of disproportionality has been acknowledged, documented and discussed over a period of decades, there is a lack of research from the voices of special educators. The purpose of this study was to describe special education teachers' experiences teaching students currently or previously enrolled in an English language learner program who are receiving special education services. This study explored teachers' views of what supports, resources and strategies contribute to student success and their views of the eligibility determination and referral process. In order to address this gap in the literature, an exploratory descriptive qualitative study was conducted by interviewing special educators. The results indicate the participants lacked support in all areas examined including professional development, resources, instructional strategies and the referral and assessment process. This study indicates structural inequity, a systematic bias in the form of a patterned and differential distribution of resources, contributing to limited opportunities for students who are English language learners who are receiving special education. Implications of the study to address structural inequity include the use of culturally responsive pre-referral strategies and knowledge of the acculturation process
\end{abstract}


when considering the needs of an ELL student who is struggling academically and incorporating culturally response teaching methods in both general and special education. 


\section{Dedication}

This body of work is dedicated to the pillars of strength

who held me up and inspired me throughout my lifetime,

the two sisters, Jere and Jean, and Grace and Eunice, for showing me the possibilities in life are limitless.

May they rest in peace. 


\section{Acknowledgements}

A special thank you to Ann Fullerton, Dannelle D. Stevens and Joanne E. Cooper for their support and encouragement throughout the years. 
Table of Contents

Page

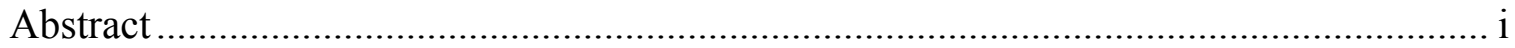

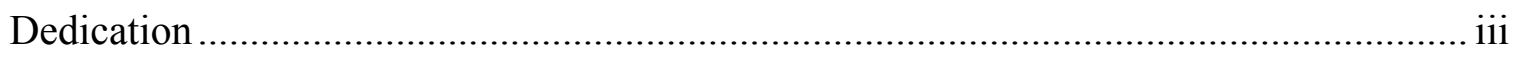

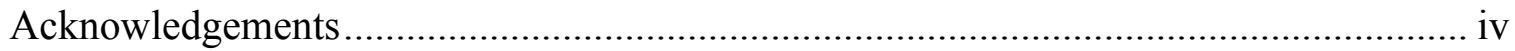

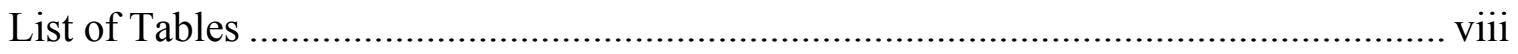

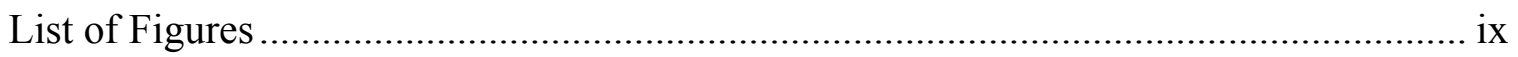

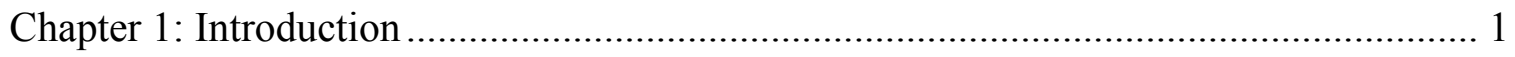

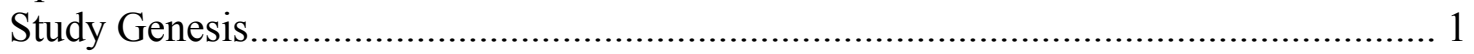

Daod's Story

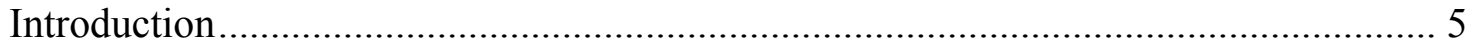

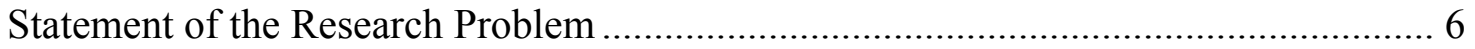

Disproportionate Referral and Placement of ELL Students in Special Education

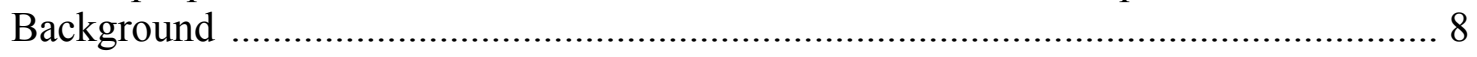

Factors and Practices Associated With Disproportionality

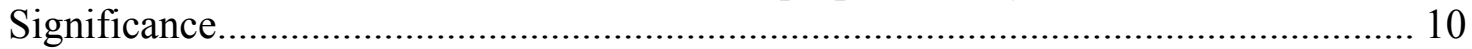

Impact of Placement in Special Education on ELL Students

Special Educators Experience With ELL Students................................................ 12

Research Methodology and Research Questions ................................................... 13

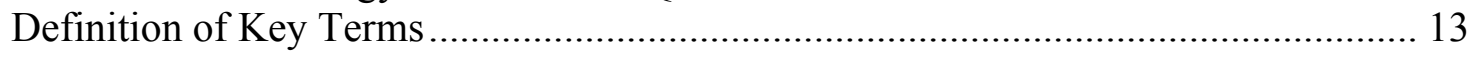

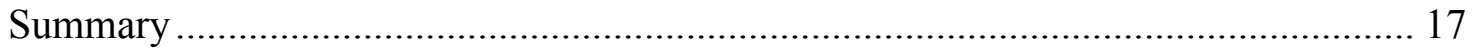

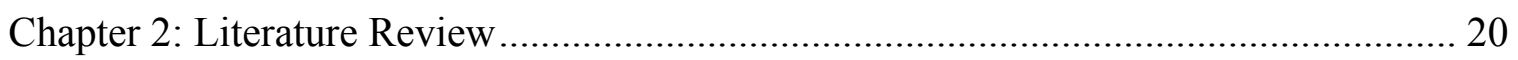

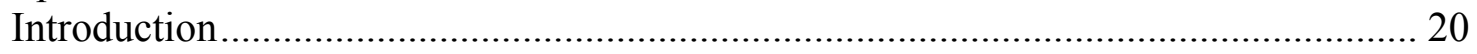

Disproportionality: Background and Importance .................................................. 21

Historical Background

Disproportionality and ELL Students

Frameworks for Understanding Disproportionality ............................................... 24

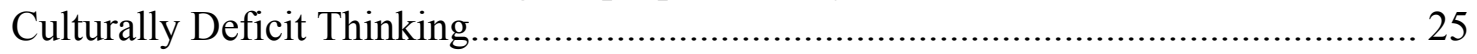

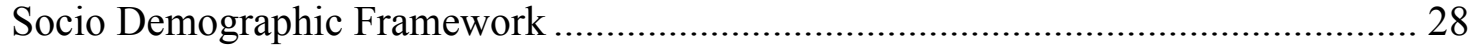

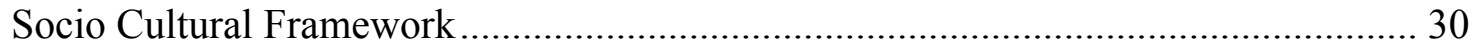

Structural Inequity Theory ............................................................................. 34

Culturally Responsive Teaching and Best Practices for ELL Students Eligible for

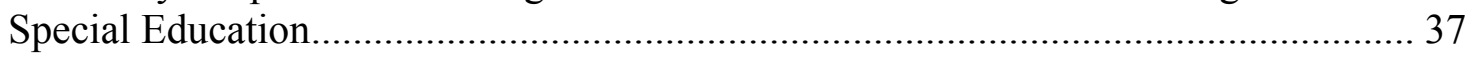

Culturally Responsive Teaching

Culturally Responsive Teaching and the ELL Student With a Disability 
Best Practices for ELL Students With Disabilities

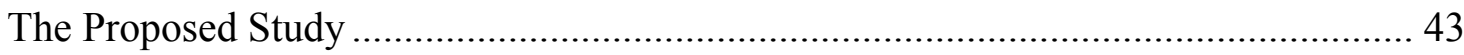

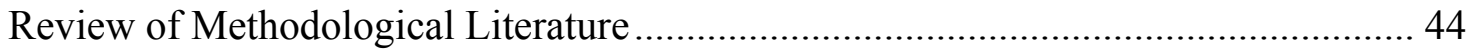

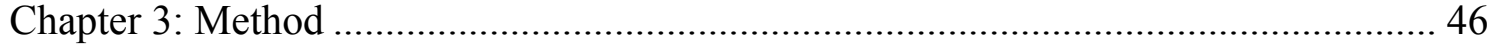

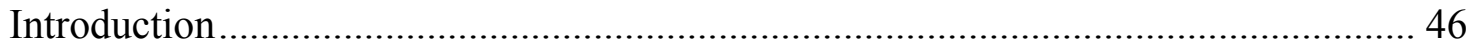

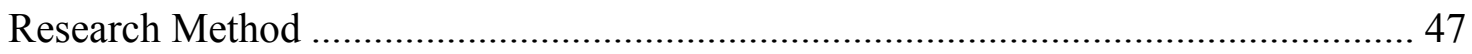

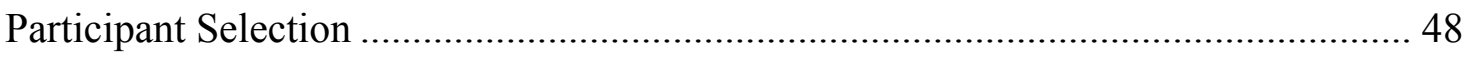

Sampling and Sampling Procedures

Institutional Review Board

Purposeful Sampling

Criterion-Based Sampling

Snowball Sampling

Details of Recruitment Procedure

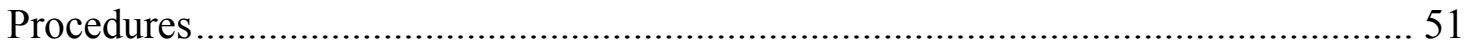

Maintaining Data

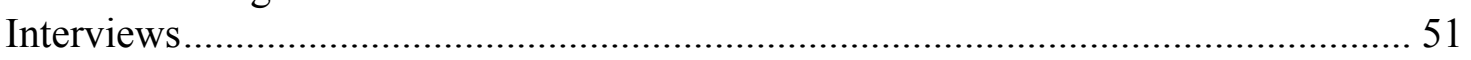

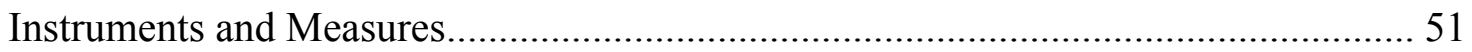

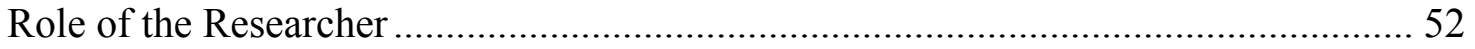

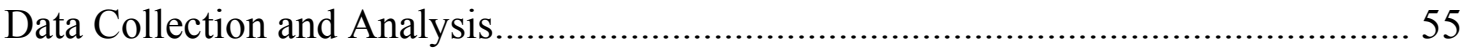

Data Collection

Data Analysis

Creditability and Trustworthiness

Member Checking

Peer Debriefing

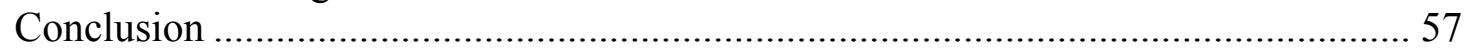

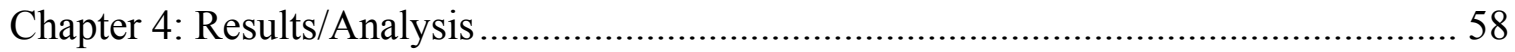

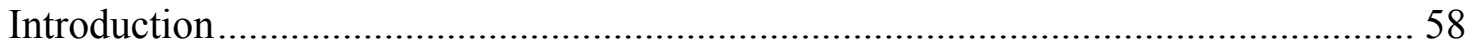

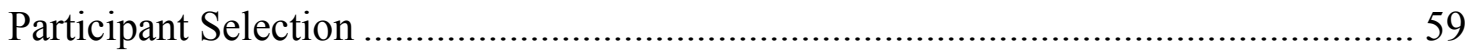

Participants' Characteristics

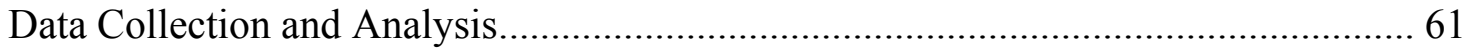

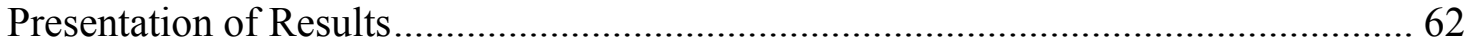

Teacher Preparation

Professional Development

Resources

Collaboration

Educational Strategies

Referral and Placement

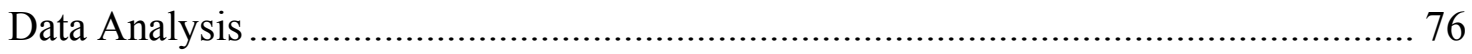

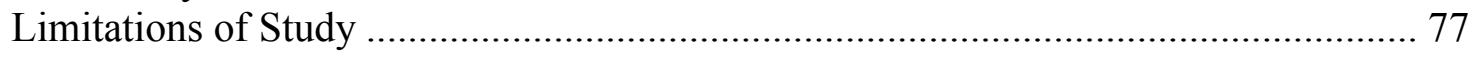

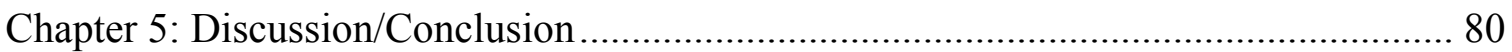

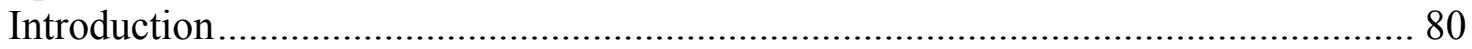




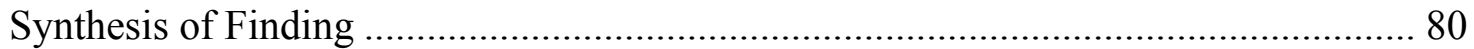

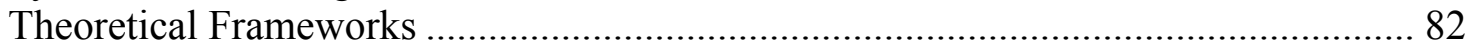

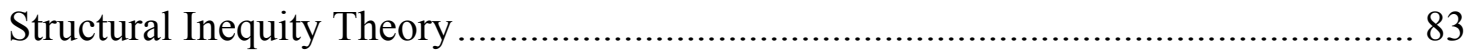

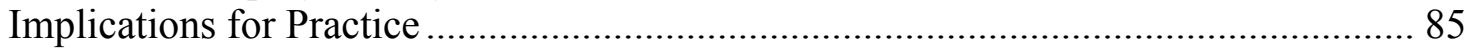

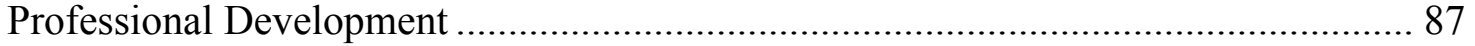

Pre-service Training

School-Based Professional Development

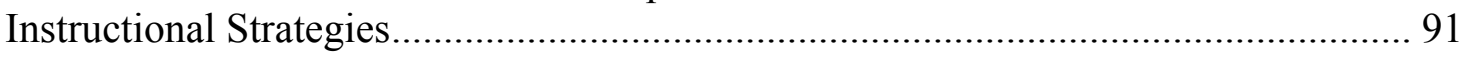

Introduction

Culturally Responsive Teaching

Acculturation

Pre-Referral Strategies

Response to Intervention

Responsive to Intervention and Cultural Responsiveness

Culturally Responsive Positive Behavior Interventions and Support

Conclusions

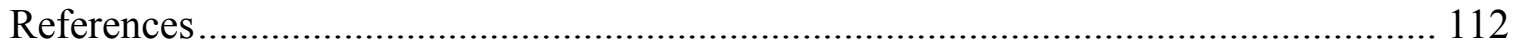

Appendices

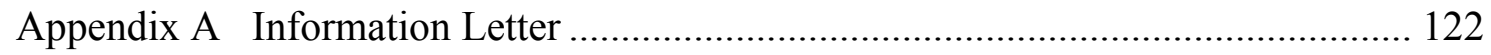

Appendix B Letter of Informed Consent .......................................................... 123

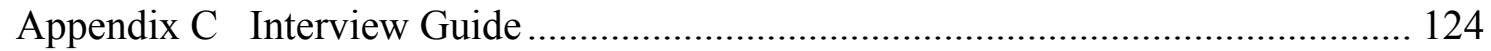

Appendix D A Self-Study Guide for Reflecting on Anti-Bias Curriculum Planning and

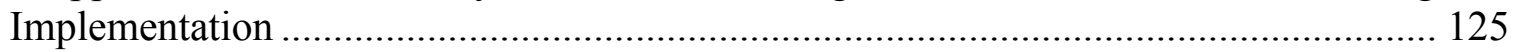

Appendix E Culturally Responsive Referral Guide............................................ 128 


\section{List of Tables}

Table $\quad$ Page

Table 1. Facts about the Student Population in Oregon......................................... 11

Table 2. Research Questions Oregon............................................................... 13

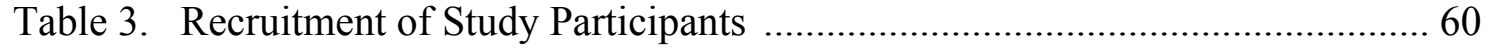

Table 4. Critical Issues to Address in Professional Development .............................. 90 


\section{List of Figures}

Figure

Figure 1. Introduction to the Problem ............................................................ 5

Figure 2. Professional Development Topics ...................................................... 89

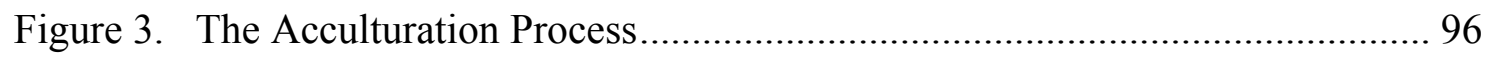

Figure 4. Response to Intervention Tiers ........................................................ 107 


\section{CHAPTER 1 \\ INTRODUCTION \\ Study Genesis}

Daod, a 14-year-old Somali Bantu student entered a special education classroom on his first day of high school in September 2009 and looked around tentatively. At first glance, he saw several students milling about who looked like ordinary teenagers but quickly noticed the students were acting just a bit odd, unusual, not like typical teenagers. One student sat at a desk talking about a character from a video game in a voice too loud for the small classroom. Another student paced back and forth on the exact same route, always ending up at the same point of departure. A tall young man repeated the same garbled phrases over and over again until the teacher understood.

As each student entered the classroom, they appeared less and less likely to resemble typical teenagers and Daod knew how typical teenagers acted, because he was one. He turned to the teacher and confidently said, "I don't belong here." She too knew that he did not belong in her self-contained special education classroom, an intensive skills center. Her other students were blissfully unaware that they were different from typical teenagers because most of her students were significantly impacted by autism and/or intellectual disability.

I was that teacher and when Daod uttered those words, I wondered how he found himself placed in my special education classroom. I also wondered how I was going to teach him because I had no training with English language learners (ELL). On the continuum of special education services from least restrictive to most restrictive, the self- 
contained intensive academic skills center is one of the most restrictive placements; the students receive specialized instruction from a certified special education teacher for $60 \%$ or more of their school day. When completing my special education teaching certificate program almost 30 years ago, there was no instruction geared at teaching students with dual eligibilities of ELL and special education. And throughout my professional career as a special educator there has been no professional development offered through the school district aimed at serving this population of students.

After carefully reviewing Daod's file, I uncovered a referral to special education that lacked process and paperwork. I discovered that when Daod was referred to special education in 2007, the referral of ELL students was made based solely on the opinion of teachers in the ELL program. The school district administration did not require a collaborative pre-referral process between special education and ELL professionals to ferret out language acquisition and relocation issues from disability as required by the reauthorization of the Individuals with Disabilities Education Act of 2004 (IDEA).

\section{Daod's Story}

Daod was born and raised in a refugee camp in Kenya where he lived with eight family members in a small tent. The children did not attend school. Life for his family was one long wait to find out which country they would be relocated to. After 10 years, while grieving for the recent loss of two of their sons, the family was relocated to Portland, Oregon. The children were enrolled in school within weeks of arriving and life became a whirlwind of new experiences and there was no cultural broker as recommended by Gay (1993) to explain the cultural systems in the United States. 
Daod was placed in a fifth grade classroom and amidst the chatter of English, he struggled to understand fifth grade curriculum and adjust to his new surroundings. He had never experienced a structured school day or sat at a desk for an extended period of time. His days in the refugee camp were unstructured and unsupervised and filled with the playful adventures of young boys. Daod and his siblings did not have a liaison to explain the intricacies of American school and culture to ease them into this new life. He was identified for services as an ELL student after completing the required assessments and attended a classroom one period a day where he received English language instruction. Daod spent most of his school day speaking his native language with his friends, other Somali Bantu students, interacting exclusively with them during and after school (O. Talasow, personal communication, October 28, 2012).

Daod changed schools twice before his seventh grade year. After two years in the U.S., his ELL teacher initiated a referral for special education and speech language evaluation based on her opinion that he was not progressing at the rate he should. To begin the formal process she requested that the building screening committee, consisting of the school psychologist, speech pathologist, special education teacher and herself as the general education teacher, conduct a special education evaluation to include a functional communication assessment, intelligence and academic tests all to be administered in English.

In Daod's file, there is no documentation of the use of evidence-based interventions as recommended by the IDEA (2004) prior to the initiation of the evaluation. Response to intervention (RTI), as an intervention model, uses the same team 
to focus on the individual student needs and designs interventions and provides ongoing monitoring prior to a request for a formal evaluation; neither this model nor any other interventions were attempted. The standardized IQ test recommended for Daod's special education evaluation was not normed on non-native English speakers yet his results were compared to native English speakers.

Daod's referral was based on the opinion of his ELL teacher. His father attended the building screening meeting where the school team decided to pursue the evaluation for special education and communication disorder, presenting him with a form in English to sign giving his permission. He later reported that he did not understand what was transpiring because the meeting was conducted with a language interpreter present who did not have knowledge of special education procedure (O. Talasow, personal communication, October 28, 2012).

Delving into Daod's educational file, I discovered a puzzling trail of documentation and lack thereof, which told the story of how he became identified as a student needing special education and speech services, after only residing in the U.S. for one and half years. Veteran educational professionals observed, evaluated and signed documents agreeing that Daod qualified for communication services as a student with a communication disorder. They determined that he qualified for special education services as a student with an intellectual disability and then designated his special education placement in the one of the most restrictive special education placements, the intensive academic skills center, a self-contained classroom. A less restrictive classroom, an 
educational resource classroom, is one of the options on the continuum of special education services yet there is no documentation to indicate that it was considered.

In Daod's eighth grade year, he attended his fourth school in three years and was bussed one hour away to a school on the other side of the city, though a middle school was located within blocks of his home, where there were no other Somali Bantu students, and attended a special education intensive academic skills center. As a high school freshman, he returned to his neighborhood school and this is when our paths crossed.

\section{Introduction}

The larger context of this study is the disproportionate number of ELL students that are referred to and placed out of general education and the ELL program and into special education (Klinger \& Harry, 2006) (See Figure 1).

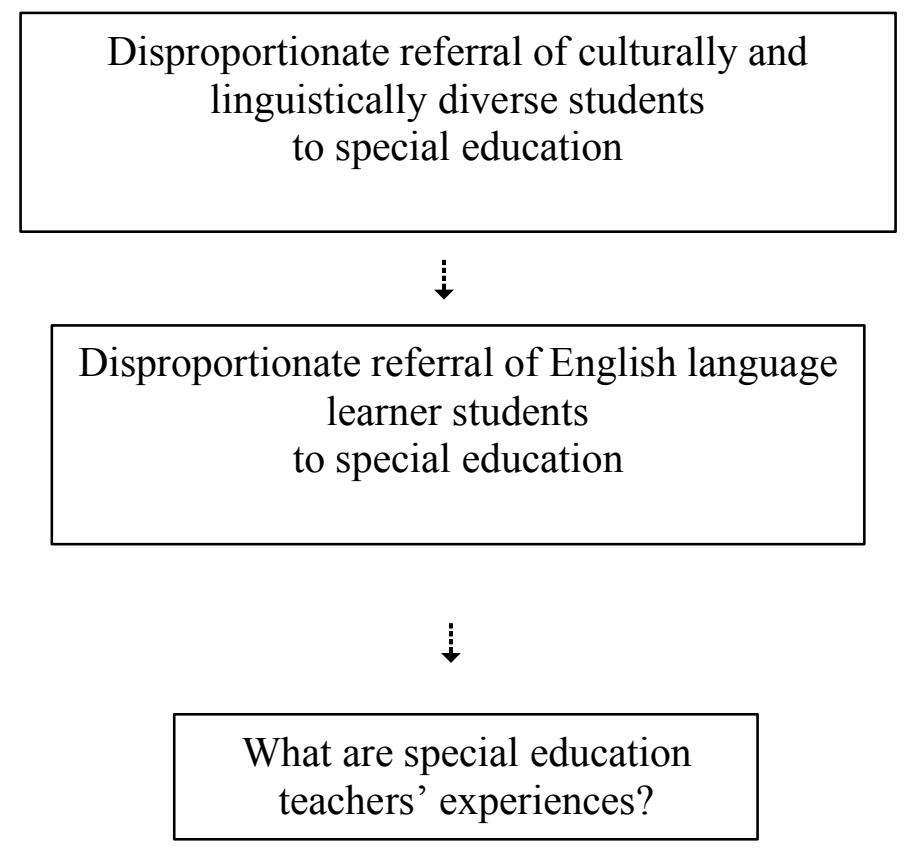

Figure 1. Introduction to the problem. 
Disproportionate refers to the percentage of students who are English language learners (ELL) in special education being larger than the percentage of ELL students in the education system as a whole. The theoretical frameworks used to understand and explain this persistent practice in U.S. schools will be discussed in chapter 2. In this chapter, the background and significance of this problem is introduced.

Although many facets of the problem of disproportionality and its consequences have been studied, an important voice is notably absent: that of special educators. We know very little about the experiences and views of special educators as they observe this process and find an increasing number of ELL students placed in their classrooms.

\section{Statement of the Research Problem}

The purpose of this study was to describe special education teachers' experiences teaching students currently or previously enrolled in an English language learner program who are receiving special education services by exploring their views of what supports, resources and strategies contribute to student success and teachers' views of the eligibility determination and referral process. The overarching research question is how are special educators teaching students currently or previously enrolled in an English language learner program who are receiving special education services?

In this section, the background and significance of the disproportionate number of ELL students being placed in special education are described. First, data documenting the phenomena of disproportionality is provided. Second, various factors and practices in schools that contribute to the problem are introduced and thirdly, the consequences for ELL students are summarized. 


\section{Disproportionate Referral and Placement of ELL Students in Special Education}

A number of researchers have suggested that there are a disproportionate number of ELL students referred to and placed in special education (Samson \& Lesaux, 2009; Sullivan, 2011). Artiles, Rueda, Salazar, and Higareda (2005) examined the 1998-1999 school year data from 11 California urban school districts to determine if there was an over representation of ELL students referred to special education. They reported that as an elementary student, ELL students were $27 \%$ more likely to be evaluated for and placed in special education as compared to native English speakers. In the secondary grades, the number increased significantly, ELL students were twice as likely to be referred for evaluation for special education services. The researchers concluded that this was a result of insufficient knowledge of language acquisition. Samson and Lesaux (2009) agreed when they suggested that teacher ratings of language and literacy skills and reading proficiency were the significant predictors for referral to special education.

The Migration Policy Institute is an independent, non-partisan, nonprofit think tank based in Washington, DC that studies migration, migration patterns and refugee policies. According to their evaluation of the most recent U.S. Census data available, in 2012 in Oregon, of the 370,537 children who were foreign born, 48\% of these children had limited English proficiency, which qualifies them for English Language services in the schools (Migration Policy Institute, 2015). According to their analyses of census data, in the state of Oregon, the increase of foreign-born persons from 1990 to 2000 was $197.3 \%$, the increase from 2000 to 2012 , was $19.7 \%$. The reauthorization of the IDEA in 2004 specifically addressed the problem of disproportionate referral of ELL students to 
special education by recognizing that numerous research studies have documented "discrepancies in the levels of referral and placement of limited English proficient children in special education" [Subpart 4, (11)(B)]. After more than a decade of acknowledgement of a disproportionate number of ELL students referred to special education, it is timely to review and report on the consequences of this problem by investigating the experiences of special educators serving this population of students.

\section{Background}

A new body of research conducted in the past two decades has investigated the referral of ELL students to special education, and researchers have found that ELL students are referred for special education evaluation and placed in special education programs at disproportionate rates in some states across the country (Artiles \& Klingner, 2006; Coutinho \& Oswald, 2000; Sullivan, 2011). The result is that increasingly special educators serve a population of ELL students whose academic needs may be language based rather then a result of disability.

\section{Factors and Practices Associated With Disproportionality}

Researchers have identified a number of factors and practices that may be responsible for disproportionately. According to Mele-McCarthy, Cutting, Leos, and D'Emilio (2005), ELL students who do not do well academically within the first few years of their arrival to the United States are often referred to special education. In Daod's story, an overreliance on the opinion of one individual and the results of tests conducted in English led to an eligibility for special education services as a student with an intellectual disability. 
Ortiz et al. (2011) examined the role that ELL teachers play in the initiation of the referral process for special education evaluation. They reviewed the school records of 90 ELL students in one district and examined the process and paperwork that resulted in the eligibility for special education under the category of learning disabled. The researchers found that the majority of ELL students were referred in the second grade because they struggled academically, specifically with language or literacy. Ortiz et al. suggested that there were a lack of interventions provided within the students' classrooms prior to a referral for special education evaluation. The ELL students were evaluated with an assessment instrument that was not normed in the students' native language or normed for bilingual students, this also was a contributing factor in their placement in special education.

Klingner and Harry (2006) observed 21 special education placement meetings for ELL students in kindergarten through fifth grade in 12 schools within a school district as part of their inquiry into the special education referral process for ELL students. After a thorough qualitative study where they examined the process and paperwork for all 21 ELL students referred for special education evaluation, Klingner and Harry concluded that there was an over reliance on test scores from assessments conducted in English and little to no discussion of other issues that affect learning, such as factors related to language acquisition, classroom environment, and instructional and management styles.

Numerous factors impact language acquisition including classroom environment, the acculturation process, length of time in the U.S., previous education, literacy in ones' native language and circumstances prior to arrival in the U.S. (Lesaux, 2006; Rueda \& 
Windmueller, 2006), none of which were considered in Daod's evaluation planning meeting for special education.

Some researchers have linked the disproportionate number of ELL students referred to special education to cultural bias in the evaluation procedures used to identify students with disabilities (Lakin \& Lai, 2012). Macswan and Rolstad (2006) found that the test measurements used may not accurately reflect an ELL student's ability. They proposed that special education evaluation teams rely overwhelmingly on assessments that are simply translated into a student's native language for administration purposes and ELL students may not have the academic language in their own native language. McCardle et al. (2005) argued that the assessments used to measure the academic skills of an ELL student to determine eligibility for special education as a student with a disability, are inherently biased (discriminatory) because the assessments were normed on native English speakers from white middle class backgrounds.

Cook-Morales, Robinson-Zanartu, and Green (2006) suggested that the use of an interventions-based assessment, as recommended by the reauthorization of the IDEA in 2004, would decrease the referrals to special education because the process considers numerous factors in a problem solving process involving parents and teachers as collaborators to target interventions. They recommended that teams compare the responses of ELL students to others from similar cultural and linguistic backgrounds.

\section{Significance}

The issue of the disproportionate number of ELL students being referred to special education is of growing importance and concern as this population increases in 
the state of Oregon. Oregon is one of only eight states in the country where the percentage of ELL students around $10 \%$ or above. The educational data from the U.S.

Department of Education, Institute of Education Sciences, National Center for Education Statistics (2013a) identifies the number and percentage of public school students participating in programs for English language learners for the 2010-11 school year as the following; Oregon 10.5\%, Hawaii 10.6\%, Alaska 11.3\%, Colorado 11.8\%, Texas 15.0\%, New Mexico 15.7\%. Nevada 19.4\% and, California 28.9\%. The average for the remaining states is $4.7 \%$.

Table 1

Facts about the Student Population in Oregon

- Total enrollment of school age children in 2011-2012 was 560,946

- $13.2 \%$ of all students received special education services

- $10.5 \%$ of students received ELL services

- $17.7 \%$ of English language learner students were also receiving special education services

Note: Adapted from ODE Statewide Report Card, 2014-2015. (November 30, 2015). Oregon Department of Education: Annual Report to the Legislature on Oregon Public Schools.

\section{Impact of Placement in Special Education on ELL Students}

Some researchers say that teachers may proceed with lowered expectations of ELL students after they are placed in special education (Gaviria-Soto \& Castro-Morera, 2005), while others say a separation from peers and placement in special education classes can be stigmatizing, increasing the alienation for a student learning a new culture and language (Klingner et al., 2005). When an ELL student is placed in special education they may be instructed in three different settings, general education, special education and the ELL classrooms (Garcia \& Tyler, 2010). Each of these three teachers may use 
conflicting strategies, dissimilar instructional methods and have a varied knowledge base regarding the influence of cultural factors that may impact ELL students' learning. The disparity among teachers can have a negative impact on the academic progress of a student.

Oswald and Coutinho (2006) questioned if special educators have the training or expertise in language development and acquisition necessary to adequately teach ELL students. While Klingner et al. (2005) reported that a special education placement can interrupt a student's language acquisition by disrupting the continuity of language development instruction when removing them from English language development classes and placing them in remedial academic classes.

\section{Special Educators Experience With ELL Students}

Though there are numerous studies examining the disproportionate number of ELL students placed in special education, there is a dearth of research on the experience of special educators as they adapt and adjust to teaching these students often without any preparation in the delivery of ELL instruction (Artiles \& Klingner, 2006). Paneque and Barbetta (2006) surveyed 220 special educators to examine their efficacy when working with ELL students and found they rated themselves the lowest on knowledge of cultural issues and support for students' native language.

It is important that special educators receive the resources and supports they need to adequately meet the needs of their ELL students. Though disproportionality has been documented in the research, the end result is that ELL students find themselves increasingly placed in special education classrooms and ultimately taught by special 
educators who do not have specific training in language acquisition and cultural issues that impact learning.

\section{Research Methodology and Research Questions}

I conducted a case study using a qualitative design to collect descriptive

knowledge of special educators' experiences and perspectives using interviews.

Table 2

Research Questions

Overarching Research Question

How are special educators teaching students currently or previously enrolled in an English language learner program who are receiving special education services?

Research Question \#1:

How are special educators prepared to teach students currently or previously enrolled in an English language learner program who are receiving special education services students?

Research Question \#2:

What resources are provided special educators teaching these students?

Research Question \#3: What strategies do special educators find promote success for these students?

Research Question \#4:

As reported by special educators, how do special educators and ELL teachers collaborate?

Research Question \#5:

What are special educators' experiences with and impressions of the referral and placement process of ELL students into special education?

Research Question \#6:

What do special educators think about the idea that there are a disproportionate number of ELL students referred to special education?

\section{Definition of Key Terms}

ELL students (English language learners). According to the U.S. Department of Education, ELL refers to a national-origin-minority student who is limited-Englishproficient. 
$\underline{\text { Students currently or previously enrolled in an English language learner program }}$ who are receiving special education services. This phrase is used frequently throughout this document because researchers found that often when an ELL student was found eligible for special education services, the ELL program discontinued service (LinanThompson, 2010; Mueller, Singer \& Carranza, 2006). Use of an acronym was considered but rejected as distracting to the reader.

English as a second language or ELL program. An educational program of techniques, methodology and special curriculum designed to teach ELL students English language skills, which may include listening, speaking, reading, writing, study skills, content vocabulary, and cultural orientation. English as a second language instruction is usually in English with little use of native language. ELL teachers complete specific requirements determined by the state department of education through a university program to receive licensure as an ELL teacher.

Culturally and linguistically diverse. The phrase "culturally and linguistically diverse" (CLD) has replaced the term "minority" to refer to students who do not identify as white.

Disproportionality. Disproportionality or disproportionate representation refers to the percentage of culturally and linguistically diverse students, including students who are English language learners, in special education being larger than the percentage of CLD students in the education system as a whole (Vasquez et al., 2011).

Measure of disproportionality compares a racial/ethnic group's risk of receiving a special education referral to the risk of the comparison group. The comparison group that 
is typically used is the group that is culturally dominant, whites. There are two statistical analyses used most often in studies of disproportionality, the relative risk ratio and the composition index. The relative risk ratio is calculated by dividing the number of students in a particular racial/ethnic category that have a specific special education eligibility by the total enrollment for that group in the entire school population (Linn \& Hemmer, 2011). Disproportionality can be assessed by analyzing the discrepancy, if the risk ratio is greater than 1.20 this indicates an over representation, 1.0 is proportionate (Bollmer, Bethel, Garrison-Mogren, \& Brauen, 2007). The comparison index answers the following question, what percentage of students who are eligible for special education services under a specific eligibility category are from a specific racial/ethnic group? (Rueda \& Windmueller, 2006).

Disproportionality can also refer to an underrepresentation of CLD students in a particular category of students with disabilities that are eligible for special education services. For example, Mandell, Ittenbach, Levy, and Pinto-Martin (2007) found that African American male youth are underrepresented nationally in the special education eligibility category of autism spectrum disorder and over represented in the special education eligibility category of emotional disturbance.

IDEA (Individual's with Disabilities Education Act of 2004). The IDEA is special education law produced by the United States Department of Education to "ensure that all children with disabilities have available to them a free appropriate public education that emphasizes special education and related services designed to meet their unique needs 
and prepare them for employment, further education, and independent living [Sec.

601(d)(1)(A)]. As stated in IDEA:

. . local agencies, and educational service agencies are primarily responsible for providing education for all children with disabilities, it is in the national interest that the Federal Government have a supporting role in assisting state and local efforts to educate children with disabilities in order to improve results for such children and ensure equal protection of the law. [Sec. (c)(6)]

Building screening committee. When a student is suspected of having a disability, they

are referred by a general education teacher or ELL teacher to the building screening committee (BSC) for discussion. The BSC committee consists of a building administrator, speech language pathologist, special education, general education and ELL teachers familiar with the student, parents, school psychologist and language interpreter. A special educator is required to attend this meeting but does not necessarily have any knowledge or experience with the student. An older student, in high school, would be invited to the meeting as well as their school counselor. After reviewing the student's attendance and grades, the team identifies the specific areas of concern. The guidelines in the IDEA (2004) require the team to develop interventions to address the specific needs of the student and implement them over a six-week period. Data is collected as the interventions are implemented and then the BSC team reconvenes to evaluate the data and add additional interventions if deemed necessary. The process repeats itself and they reconvene again, after a discussion the committee may conclude that a special education evaluation is appropriate and refer the student for testing. Signed permission is sought from the parent to complete academic testing including measures of intelligence and the parent commits to obtain a physician statement to consider if the student has any medical issues that impact their ability to learn. 
Special education. Special education refers to specialized instruction provided by a certified special education teacher. To receive specialized instruction, a student must have a special education eligibility and a written individualized educational plan (IEP) containing goals and objectives to address the student's needs. This document is created with input from the student's IEP team which consists of both a general and special education teacher, any specialist the student qualifies for including Speech Language Pathologist, Occupational Therapist, Physical Therapist as well as the parent as an equal member of the team. When the student is 14 years or older, they are invited to become a member of the IEP team.

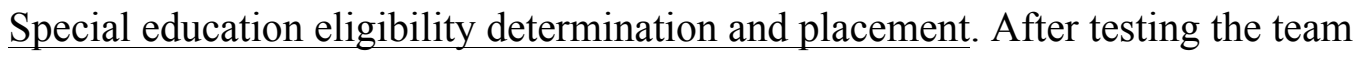
reconvenes to review the testing results. Based on the information obtained from the student's physician and the academic test results, the team may conclude that the student needs specialized instruction and should be placed in special education. If the team agrees the results warrant this conclusion, they determine which special education eligibility fits the student and what special education placement is most appropriate.

\section{Summary}

The Oregon Department of Education has reported that from 1997-1998 to 20092010 the ELL student population being served in Oregon schools increased by $387 \%$. There is mounting research explaining the various issues that impact learning as these newcomers assimilate and acculturate to the United States (Garcia \& Cuellar, 2006). As immigrant families settle into towns across the state, their children enter the school system where they are identified as ELL students following a referral process. This 
designation allows the students to participate in English language development delivered by a certified ELL teacher specifically trained in English language acquisition and development. A mounting body of research documents the increasing referral of ELL students to special education within two years of their arrival to the U.S. resulting in disproportionate referral and placement of ELL students to special education (Artiles et al., 2005; Overton, Fielding, \& Simonsson, 2004). The vocabulary has changed; researchers now use the term disproportionality instead of over representation, the phrase culturally and linguistically diverse (CLD) has replaced the term minority, and intellectual disability supersedes mental retardation, yet the problem remains the same; nationally there is a disproportionate number of CLD students in special education (Artiles \& Trent, 1994; Cook-Morales et al., 2006; Coutinho \& Oswald, 2000). As a consequence, special educators become increasingly responsible for the academic success of ELL students.

In the next chapter, research is reviewed that provides context and background for the research questions and the analysis of the special educators' interview responses. First, the history of the research on the disproportionate referral of CLD students to special education is presented and how it evolved to include ELL students. The predominant frameworks (theories) that have been developed to explain the persistent disproportionality in U.S. schools are described. These provide important background for analyzing the special educators' experiences when teaching students currently or previously enrolled in an English language learner program who are receiving special education services. Second, the current understanding of research based instructional 
strategies for special educators serving ELL students is summarized. This provides a foundation for analyzing the special educators' description of their instructional and support needs. 


\section{CHAPTER 2}

\section{LITERATURE REVIEW}

\section{Introduction}

As policies change and districts adapt, educators' practices adjust to the latest philosophy and methods. Politicians grapple with educational policy and special educators teach, every day, to a widely diverse student population with a vast set of skills, abilities and cultural values. Special educators meet their students where they are every day with increasingly limited materials and resources, often in classrooms that were built when no one could envision how many students would pack into the classroom space. Special education classrooms have gone from the corner in the basement to the main hallway of a school. As national discourse abounds, special educators' voices are lost in the flurry of reforms, ideas and arguments because they are busy in their classrooms serving students, every day. The purpose of this study was to describe special education teachers' experiences teaching students currently or previously enrolled in an English language learner program who are receiving special education services by exploring teachers' views of what supports, resources and strategies contribute to student success and their views of the eligibility determination and referral process.

Chapter 2 is organized into three sections. In the first section, the historical and current context for the proposed study is provided. In the second section, the major frameworks researchers have examined to account for persistent disproportionality in U.S. schools are described. Then in the third section, expert opinion regarding the best practices for teaching ELL students, including students placed in special education, are 
summarized. When the participants' responses to the research questions were analyzed, this literature review served as the foundation for themes that emerged from the special educators' interview responses.

\section{Disproportionality: Background and Importance}

\section{Historical Background}

There is an almost 50 year history of literature examining the disproportionate number of referrals of culturally and linguistically diverse (CLD) students to special education (Artiles et al., 2005; Dunn, 1968; Linn \& Hemmer, 2011; Sullivan, 2011). While reviewing the research, I followed the academic journey of key researchers who have persistently pursued this topic over decades. In 1968, Dunn first reported on the disproportionate number of CLD students placed in special education. At that time, there was documented evidence that African-American male youth were referred to special education with an eligibility of what was then called "mental retardation" and placed in special education classrooms at a higher rate than their white peers. Dunn's article is the seminal article on the topic of disproportionality in special education and is cited in almost all articles on this topic.

In the 1970s and 1980s, disproportionality research focused on the prevalence of African-American male youths' placement in special education programs (Blanchett, Klingner, \& Harry, 2009). As the U.S. Latino population grew in the 1990s, research followed focusing on the disproportionate number of Latino male students placed in special education classrooms (Artiles \& Trent, 1994). The No Child Left Behind Act of 2001 mandated that districts disaggregate their data along racial and ethnic categories so 
that a measure of how different groups of students are performing relative to each other and to the whole could be assessed. With the passage of the IDEA in 2004, research on disproportionality in special education significantly increased as this document called for states to address the disparate academic performance of students with ethnic, cultural, racial and linguistic differences.

\section{Disproportionality and ELL Students}

Studies conducted in the past two decades shed new light on the disproportionate number of English language learners (ELL) referred to and placed in special education (Samson \& Lesaux, 2009). Klingner and Artiles (2006) argued that there is a lack of knowledge among school professionals about the difference between language acquisition and learning disability leading to inappropriate referrals of ELL students for special education evaluation. Artiles, Kozleski, Trent, Oscher, and Ortiz. (2010) agreed and contended that a lack of understanding about culture, language acquisition and prereferral strategies drove a disproportionate number of referrals of ELL students for special education.

There are numerous researchers examining the increasing number of ELL students who are being referred to special education. Some have linked the disproportionate number of referrals to the use of assessments to identify disability as culturally irrelevant and inherently biased for use with CLD students including ELL students (Abedi, 2006). Klingner and Harry (2006) found that evaluation teams relied overwhelmingly on standardized intelligence tests normed on native English speakers from white middle class backgrounds. Some researchers have concluded that this is a discriminatory and 
inappropriate use of assessment instruments for making eligibility determination and placement decisions (Adebi, 2006). Cook-Morales et al. (2006) suggested that the use of interventions-based assessments would decrease the referral of CLD students to special education. They proposed that educators target interventions after completing a problem solving process involving both parents and teachers as collaborators and recommended that teams compare the responses of ELL students to others from similar cultural and linguistic backgrounds. According to McCardle et al. (2005), the pre-referral process varies from state to state and often students identified for ELL instruction who do not do well academically within the first few years of their arrival to the U.S., are targeted for referral to special education.

Other researchers have questioned the validity of some referrals of ELL students to special education. Ortiz et al. (2011) reviewed the data of 90 ELL students placed in special education in one school district to determine how referral decisions were made. General education teachers referred ELL students in the second grade when they believed the students were exhibiting academic, language or literacy issues. The researchers explained that students in early elementary school have had little exposure to the general education reading curriculum. They postulated that the referrals were premature. All of the 90 students were assessed for a learning disability using an instrument developed in English by the districts' speech and language pathologists and then translated into Spanish; the assessment was not normed in either language. This was the only measurement the school district used to determine a student eligible for special education in the category of learning disability. When the researchers examined archival data, $77 \%$ 
of the students previously identified for special education as learning disabled no longer qualified when standardized measurements were used. This study investigated inappropriate practices that led to the erroneous and systematic placement of ELL students in special education classrooms in one school district.

\section{Frameworks for Understanding Disproportionality}

In this section of the literature review, the predominant frameworks found in the research on disproportionality in special education are presented. It was important to delve into all of the frameworks developed to understand disproportionality because when interviewing special education teachers, it was possible that multiple frameworks would surface as related to their experiences as teachers.

Theoretical tools provide a powerful means of understanding the roots of this perplexing problem and offer a critical lens for understanding how supposedly equity-minded policies, such as special education law, become a means for perpetuating racial inequity and offer a means of conceptualizing the factors that either foster or impede positive change. (Sullivan \& Artiles, 2011, p. 1548)

While conducting this literature review four principal frameworks emerged to explain disproportionality in special education and why this problem persists, cultural deficit thinking, socio demographic, socio cultural and structural inequity theories. Waitoller, Artiles, and Cheney (2010) reviewed 42 research studies examining disproportionality in special education published between 1968 and 2006 and found that they could categorize all of the research into three frameworks; cultural deficit thinking, socio demographic and socio cultural theories. A fourth framework, structural inequity theory, challenges the work of previous researchers, and presents some provocative ideas. Sullivan and Artiles (2011) reviewed decades of disproportionality research and found that most scholars did not discuss the issue with the use of a theoretical framework. 
Sullivan and Artiles have embraced the structural inequity framework as necessary to clarify the problem of disproportionality, predict outcomes and guide efforts to change the rate of disproportionate referrals of CLD students including ELL students, to special education. In this section the four frameworks for understanding disproportionality are described and the research findings used to support each framework are presented.

\section{Culturally Deficit Thinking}

Every district constructs and employs notions of what it means to be academically successful in their district; however, these notions are also rooted in cultural frameworks that are based on the experiences of the dominant group. (Ahram, Fergus, \& Noguera, 2011, p. 2247)

Culturally deficit thinking is represented by school staffs' characterization of lowincome students and/or CLD students including ELL students as psychologically abnormal. Deficit thinking blames school failure on the students, their parents, background and families (Walker, 2011). All students are compared academically and behaviorally to white middle class students. Any differences in the behavior of CLD students are attributed to deficits in their ability and potential. Teachers have cultural beliefs based on their own cultural view about what they think is appropriate and may view a student's behavior, communication, appearance and expression through their own cultural lens. Teachers may presume deficiencies in cultures they are unfamiliar with and their own cultural background may bias their interpretations and decisions regarding what they believe to be appropriate. Perceptions of students' ability can be clouded unknowingly by cultural bias and ultimately influence students' ability to gain access to opportunities to learn. Some researchers have proposed that teachers may have lower expectations of students' abilities and the potential of students based on their cultural 
deficit thinking (Ahram, Fergus \& Noguera, 2011). A commitment by school district central office administration to thoughtfully initiate institutional changes can interrupt the influence of culturally deficit thinking (Ahram et al., 2011).

In their review of the literature, Waitoller et al. (2010) concluded that beliefs about race, bias school district staffs' perceptions of CLD students. They examined studies in which researchers analyzed observational data, special education eligibility reports, transcripts of meetings and interviews and determined that cultural deficit thinking contributed to special education placement decisions made by school teams and the disproportionate number of CLD students referred to special education.

In 2011, Chu also conducted a literature review to investigate the relationship between teachers' perceptions of CLD students and their referral of these students to special education. He found that teachers' cultural deficit thinking influenced their expectations of CLD students' academic potential and increased the number of special education referrals for these students. Teachers' expectations, attitudes, and beliefs about their CLD students affected their interpretation of students' behaviors and skills. He also found that teachers perceived CLD students' linguistic, cultural and social differences as negative factors.

Between the school years of 2004-2005 to 2006-2007, the New York State Department of Education found that in 90 of their school districts, African American and Latino students were twice as likely to be found eligible for special education under the category of learning disability as compared to white students (Ahram et al., 2011). In 44 other school districts, the rate of referral, evaluation and placement into special education 
for African American and Latino students was four times more likely than white students. Because of this vast discrepancy, the New York State Department of Education embarked on a 5-year project with the Technical Assistance Center on Disproportionality based at New York University with the purpose of identifying the root causes that perpetuated the prevalence of disproportionality in their state. After the researchers investigated and determined the root causes they were tasked with developing and providing interventions to significantly address and reduce the disproportionate number of referrals of CLD students to special education.

Ahram et al. (2011) of New York University began by conducting teacher interviews and surveys in two suburban New York school districts. They also analyzed district policy when looking for the root causes of disproportionality. When analyzing the data, they found that cultural deficit thinking affected teachers' beliefs. Bias related to race and socioeconomic status determined their lower expectation of their CLD students. Any attempts by the school districts to address disproportionality were superficial, short term and ineffective as they did not specifically address teachers' beliefs. Among Ahram et al.'s numerous conclusions were: there were inadequate institutional safeguards in place to prevent inappropriate referrals to special education, teachers were overwhelmed and lacked support, interventions were poorly documented, inappropriate screening tools were used and the referral process was inconsistent across the school districts.

They concluded their investigation by determining that cultural deficit thinking was the root cause of the disproportionate number of referrals of CLD students to special education. To address their findings the Technical Assistance Center on 
Disproportionality based at New York University, implemented a long-term program of professional development. Their research indicated that an in-depth program would be beneficial and promote real change. They developed 40 hours of training sessions to include additional technical assistance, on-going focus groups and one on one support to teachers.

In conclusion, some researchers contended that when teachers perceived their CLD students through their own cultural lens they viewed cultural and linguistic differences as deficits; they are therefore more likely to refer their CLD students for evaluation for special education. Teachers who develop self-awareness of their own culture are then able to appreciate cultural and linguistic differences and incorporate them into their teaching.

\section{Socio Demographic Framework}

Over representation becomes a problem when it reflects a situation of bias when the probability of being in a special education placement because of personal characteristics of a subject is greater simply by reason of belonging to a certain ethnic minority. (Gaviria-Soto \& Castro-Morera, 2005, p. 542)

The socio demographic framework views disproportionality as the result of socio demographic factors which include eligibility for free or reduced lunch, parent's income and education, poverty level of the community and the racial makeup of the school and community. When Waitoller et al. (2010) examined 42 research studies examining the over representation of CLD students in special education, published between 1968 and 2006, they found that the socio demographic framework accounted for disproportionality in $33 \%$ of the studies. In these studies, the researchers approached the issue of the disproportionality by looking closely at the individual, community and family factors of 
the students. The researchers conducted qualitative studies examining transcripts from eligibility meetings and special education eligibility paperwork as well as interviewing school staff and observing special education eligibility meetings. Artiles et al. (2010) contended that attributing disproportionality to these factors is a belief aligned with white middle class values in assuming that these factors deem a student to failure while not recognizing the goals' cultural communities have for their children, in spite of these factors. Others suggest that the poverty experienced by some newcomers to the U.S. causes developmental threats and stressors that lead to learning disabilities (MacMillan \& Reschly, 1998).

In 1994, Artiles and Trent completed a study examining special education referrals to special education and reported that evaluation teams focused on the factors identified above rather than acknowledging the relationship between culture and learning, culturally different learning styles and bilingual language development. They explained that the relationship between culture, learning and social interactions can impact how a predominately white middle class school staff will perceive a CLD student and their potential to succeed in a general education setting.

Coutinho, Oswald, and Best (2002) identified nine socio demographic factors present in a school community to include: student-teacher ratio, per-pupil expenditure, percentage of children enrolled and considered at risk, percentage of students enrolled who were non-white, percentage of students enrolled with limited English proficiency, median house values, median income, percentage of households below the poverty level and percentage of parents who had no high school. They investigated whether these 
factors had an impact on the probability of referral and placement in special education by reviewing the data collected by the U.S. Department of Education for one school year and their results indicated that a communities' socio demographic factors did increase the possibility of CLD students being referred to special education.

The socio demographic framework attributes disproportionality to socio demographic factors. Some researchers believe that this view unfairly compares CLD students' individual, community and family factors to those of white middle class students thereby perpetuating the perspective that there is only one valid worldview.

\section{Socio Cultural Framework}

Socio cultural factors associated with the acquisition of a second language are overlooked when evaluating ELL students for special education. (Artiles \& Klingner, 2006, p. 2189)

When looking at research through the socio cultural lens, the school district structure and racial and political economic factors related to race and racial issues are identified. School structure includes the enrollment and demographics of the school district and community, the number of students identified for special education services, desegregation policies and the number of white students who attend private schools. Coutinho and Oswald (2000) argued that the special education process is culturally and linguistically biased causing students' achievement and behavior to be judged differently across ethnic groups. They further reported that based on their research they found that, the teachers who initiated student referrals to special education and the eligibility team members who then determined eligibility, allowed their bias to interfere with their interpretation of student behavior, achievement and assessment results. 
Dr. Alfredo J. Artiles of Arizona State University is one of the first researchers to investigate the disproportionate number of ELL students placed in special education and one of the most predominate and prolific scholars in this area who has doggedly pursued this topic for decades. He often worked with the late Dr. Janette K. Klingner of the University of Colorado at Boulder, who was also one of the predominate researchers in the area of disproportionality. She too was one of the first researchers to investigate the referral of ELL students to special education. In one of her articles she stated, "power and hegemony play a significant role in the educational experiences of culturally and linguistically diverse students in U.S. schools" (Klingner et al., 2005, p. 6). She went on to say that "basic assumptions about race, worldviews, beliefs and epistemologies serve to perpetuate disproportionate representation” (Klingner et al., p. 6). In a study Klingner and Artiles published with six other researchers, they took the position that the use of the standard IQ tests to evaluate students' intellectual capabilities perpetuates disproportionality because these measures reflect the dominant culture, which is white culture (Klingner et al.). They argued that the expectation that ELL students will perform within the same normative parameters as the white middle class subjects these tests are normed on, is an inappropriate assumption. They made the point that because there are social and culture aspects of learning uniquely experienced by CLD students, they should not be compared with white middle class students who do not share the same experiences.

Klingner and Harry (2006) observed special education evaluation meetings for 21 ELL students in kindergarten through fifth grade, in twelve schools within a school 
district. Using a qualitative design, they took detailed notes while attending evaluation meetings, conducted classroom, home and community observations and interviewed students, parents, bilingual assessors, school psychologists, and building, bilingual education and special education administrators. They observed how each team functioned, the roles of various team members and the school staffs' interactions with the parents of the referred student. They noted a lack of consistency in the process of special education referral, assessment and eligibility determination across schools in the district. In addition, Klingner and Harry examined psychological reports, special education paperwork, students' individual education plans (IEPs), student test protocols and student work samples. Their overarching research question was; was bilingual development considered by school teams and what was their level of knowledge regarding second language acquisition?

They found that the school district completed a pre-referral screening process for ELL students prior to initiating referrals for evaluation for special education. A limitedEnglish-proficiency committee and a bilingual assessor prescreened the students' referrals, prior to sending the referral to the building screening committee (BSC) meeting. The BSC consisted of a general and special education teacher, parent or caregiver, administrator, and was optionally attended by a school psychologist, counselor or social worker.

The researchers found that knowledge of language acquisition versus learning disability varied among school staff significantly across the school district. Inconsistency was found in numerous areas including the understanding of the district procedures 
concerning when to refer a student for a special education evaluation. They observed that often there was limited understanding of the language acquisition process and at times there was little to no discussion of language issues and what the student's skills were in their native language. Frequently, a school team referred an ELL student for special education evaluation because of an assumption that their learning difficulties were due to low intelligence or learning disabilities and did not even consider language issues.

Klingner and Harry (2006) concluded there was an over reliance on the test scores of assessments given in English. Other factors that affect learning such as classroom environment, instructional and management styles were not considered. At most of the meetings they observed, there was no discussion of how the student performed academically in their native language. The teams relied overwhelmingly on the school psychologist and the results from a standardized intelligence test, which was given in English. Often the decision to place a student in special education was made prior to the meeting with no input from the parent. At many meetings no translation services were offered and when they were offered, the translator had no knowledge of the referral process. The special education eligibility documents, test results and narrative explanation of the tests were not translated into the parent's native language. The school teams ignored the socio cultural factors that influence CLD students learning.

According to Garcia and Tyler (2010), when ELL students are assessed using cultural norms of the dominant white culture, their socio cultural differences are negated. They identified socio cultural factors that affect the way ELL students may process information, they are: use of logic (spiral vs. linear), how students interact with others 
(collectivistic vs. individualistic), how students communicate (direct vs. indirect) and how students learn (holistic vs. analytical). Garcia and Tyler explained that these socio cultural factors can influence how both an ELL student's learning is perceived and how they fare on assessments used to measure learning and intelligence. The socio cultural framework asserts that when assessment and teaching practices ignore socio cultural factors that influence learning and teaching, CLD students are not fairly or appropriately educated.

\section{Structural Inequity Theory}

Schools promote the interests of the most privileged students while undermining the interests of the culturally diverse student. (Ahram et al., 2011, p. 2236)

Despite decades of professional development on bias and numerous reforms, disproportionality continues and some researchers have stated that it is time to look at the practices and policies in schools at the organizational level. Structural inequity theory explains that bias at some level within the educational system leads to disproportionate identification and special education placement rates for students of color, CLD and ELL students (Artiles, 1998). Sullivan and Artiles (2011) argued that structural inequity theory provides a way to understand the persistent racial inequity in special education. They further explained that systematic bias refers to a patterned and differential distribution of resources, life chances and costs/benefits among groups of the population that result in structural inequities. Sullivan and Artiles referred to a "sorting process that underpins special education identification" (p. 1531). Professional decisions that take place in this system can cause differential treatment among racial groups. Biased racial outcomes associated with policies and practices are the result of institutional racism. Inequity can 
be a means of maintaining educational stratification and this results in racism that, in turn influences the behavior of individuals within the system. The racial group in the position of the most power benefits and institutional racism is the result. Special education has been used to perpetuate the marginalization of students from minority racial/ethnic groups or limit their access to general education peers and curricula (Artiles \& Bal, 2008). Sullivan and Artiles discovered that patterns and predictors of disproportionality may differ across localities but the root cause is the same, structural inequity.

Bonilla-Silva (1996) defined structural inequity theory as racialized social systems. They explained that a racialized social system exists when access and opportunities for individuals are based on their race, and that the race in the dominant position (whites) receives greater access to opportunities. Structural racism as defined by Bonilla-Silva has the following characteristics: it is covert, embedded in normal operations, avoids direct racial terminology and is invisible to most white persons.

Beratan (2008) proposed that the IDEA of 2004 itself perpetuates institutional racism by giving a financial incentive to school districts to over identify students for special education services so that they can receive federal monies, "the disproportionate identification of minority students as disabled serves as a bounty that actively encourages over identification as a means to higher funding levels" (p. 346). They contended that the disproportionate number of CLD students identified for special education services began decades ago as a response to the mandate to desegregate; CLD students were then placed in special education classrooms in disproportionate numbers as a means to segregate them. Beratan (2008) argued that there is a long history of African American male youth 
being identified and placed in special education at a high rate in reaction to the mandate to desegregate schools. They made the following argument that "the development of special education can be seen as primarily serving the white interest of reformalizing segregation" (p. 348).

Disproportionality in special education has been examined from various perspectives for an almost 50 year period. ELL students have been included in the discussion among researchers in the past two decades as a disproportionate number of ELL students are referred to special education. Dr. Alfredo J. Artiles of Arizona State University has stated a need for researchers investigating this topic, to embrace the structural inequity framework because he believes there is a need for a unified theoretical tool to guide future research. After decades of reform and professional development on cultural bias, there is no resolution to the problem of the disproportionate referral of CLD students to special education and specifically ELL students.

The structural inequity framework attributes disproportionality to institutional racism that is deeply embedded in the educational system and cites the long history of disproportionate referral of CLD students to special education as evidence.

The four predominant frameworks that have been proposed to explain disproportionality were reviewed. These frameworks were described because they served as the foundation for the thematic analysis of special education teachers' interview responses regarding their experiences with the eligibility and special education placement process for ELL students. Four frameworks including culturally deficit thinking, socio 
demographic and socio cultural factors, and structural inequity theory were considered when analyzing the participants' responses regarding their experiences and views.

\section{Culturally Responsive Teaching and Best Practices for ELL Students Eligible for Special Education}

In this section culturally responsive teaching and the current understanding of best practices for special educators serving ELL students is reviewed. This summary of expert opinion from the fields of culturally responsive practice, ELL instruction and special education provide a foundation for the later analysis of the special educators' descriptions of their instructional practices and support needs. First, culturally responsive teaching is defined and described as an important best practice for all students and then applications of culturally responsive teaching with ELL students with learning disabilities are discussed. Second, other best practices described in the literature for teaching ELL students receiving special education services are summarized.

\section{Culturally Responsive Teaching}

The essence of culturally responsive pedagogy for ethnically diverse students is using, multiple and varied culturally informed techniques in teaching African-, Asian-, and Latino Americans. (Gay, 2002, p. 625)

Culturally responsive teaching is "using instructive programs and practices that reflect students' cultural heritages, experiences, and perspectives . .." (Gay, 2002, p. 613). Some experts explained that approaching CLD students including ELL students from the perspective of a culturally responsive pedagogy would greatly reduce the number of CLD student, referred for special education evaluation (Chu, 2011; Gay, 2002; Klingner \& Soltero-Gonzalez, 2009). Others suggested using culturally responsive 
pedagogy as the predominant framework to guide teacher instruction when working with all students in today's increasingly diverse schools (Wlodkowski \& Ginsberg, 1995).

In 1995, Wlodkowski and Ginsberg developed a model of culturally responsive teaching based on the premise that there is a strong relationship between culture, motivation, language, beliefs, values and behaviors. They maintained that one's culture permeates all aspects of our lives. The model they proposed consisted of four conditions including; establishing inclusion, developing a positive attitude about cultural differences, enhancing meaning by including curriculum of high interest to CLD students and promoting competence. In Gay's (2002) work she expanded their four components and stated that culturally responsive teaching can be applied in a special education setting. Gay maintained that one's culture affects one's values, communication, socialization, and learning styles. The four components she has identified are; critical cultural consciousness, culturally responsive classroom environment, diverse community of learners and multicultural curriculum content and instruction.

Gay (2002) expressed that to become critically culturally conscious, teachers need to become aware of their own cultural assumptions and beliefs and how these affect their attitudes and behaviors towards students from cultures different from their own. Culture influences how we learn, beliefs, values and how we interact with others (Klingner \& Soltero-Gonzalez, 2009). To incorporate students' cultures into their teaching and classroom environment, teachers need to gain knowledge of all of their students' cultures (Gay). 
A culturally responsive classroom is an emotionally safe, warm and caring environment where expectations are high and students receive encouragement in the form of verbal praise and acknowledgement of their successes (Gay, 2002; Klingner \& Soltero-Gonzalez, 2009). Students are surrounded with visuals that reflect positive images from their cultures. In a classroom with a diverse community of learners it is important for teachers to match their teaching styles to the learning style of the students; cooperation and collaboration are fostered rather than competition (Gay). Klingner and Soltero-Gonzalez agreed when they reported the need to recognize the role culture plays in learning. A student is socialized within their culture on how to learn and these ways of learning may vary from the dominant culture; if the instructional style is incompatible with the way they approach learning in their culture, there is a mismatch and this can be interpreted as disability (Klingner \& Soltero-Gonzalez). And lastly, in a culturally responsive classroom, multicultural curriculum is used to teach about the history, cultures, contributions and experiences of students from the various ethnic groups represented in the classroom (Gay).

Brown (2007) explained the need for educators to learn factual information about the cultural particularities of the specific ethnic groups represented by students in their classrooms. Blanchett, Klinger and Harry (2009) agreed stating that when educators understand how race, culture, language and class affect learning, they become ready to provide culturally responsive instruction.

If teachers become more culturally conscious and competent then fewer African-, Asian-, Latino-, and Native American students will be misplaced in special education, their disproportionate representation will diminish, and those who are 
appropriately assigned to special education will have a better chance of receiving the quality of education they rightfully deserve. (Gay, 2002, p. 627)

\section{Culturally Responsive Teaching and the ELL Student With a Disability}

The need to incorporate culturally responsive pedagogy into pre service and in service training was recommended by Coutinho et al. (2002) after they analyzed U. S. Department of Education data for one school year and found that CLD students across the country were disproportionality referred to special education.

Chu (2011) conducted a literature review to investigate what characteristics educators who were successful with CLD students demonstrated and found two characteristics identified as cross cultural competencies. Successful classroom teachers showed an understanding of their own personal beliefs and of their students' worldviews, beliefs and attitudes. Educators possessing these two characteristics considered students' cultural and linguistic needs when choosing intervention strategies and techniques and believed that all of their students could learn and therefore were not likely to refer their CLD students for special education evaluation.

School districts must invest in resources for educators to learn about the cultural, communication and language norms of their CLD students and recognize that hopes and dreams of CLD families for their child with a disability may be different from the predominant cultural group (Blanchett et al., 2009). Hoover and Patton (2005) proposed that there is a need for school districts to provide tools for educators to develop culturally responsive teaching practices to promote the academic success of ELL students identified for special education services. They identified numerous factors that are important when differentiating curriculum and instruction including knowledge of family structures, 
interpersonal relationships, gender responsibilities, values, religion, traditions and historically significant events in a student's culture. Instead of perceiving difference as deficit, Klingner and Soltero-Gonzalez (2009) suggested that these factors as well an ELL students' prior knowledge and interests be incorporated into a culturally responsive classroom to make learning relevant to students' lives.

\section{Best Practices for ELL Students With Disabilities}

Research has shown that no one teaching strategy will consistently engage all learners. The key is helping students relate lesson content to their own backgrounds. (Wlodkowski \& Ginsberg, 1995, p. 17)

In the decades that disproportionality in special education has been investigated, experts have determined best practices when serving ELL students with learning disabilities as well as made recommendations as to how best assess for true learning disability.

To work effectively with ethically, culturally and linguistically diverse individuals with developmental disabilities and their families, educators and service providers must be aware that special education is a cultural institution that may or may not reflect the values, beliefs and cultural perspectives of all parents. (Blanchett et al., 2009, p. 401)

Garcia and Tyler (2010) described research based strategies to address the unique needs of ELL students receiving special education, they included presenting instruction in various modalities (listening vs. reading, oral reports vs. written) and breaking up reading passages into smaller more manageable chunks to reduce the amount of information students need to report on. These are strategies that are used typically by ELL instructors that can be adapted by special educators. They also recommended system changes to address ELL students' needs in special education, specifically, the need for building and 
central office administrators to provide the time, tools and resources that will promote collaboration between general education, special education and ELL teachers.

Hart (2009) suggested that there is a need for bilingual special educators who have the ability to deliver instruction in English and a student's native language. These bilingual special educators could accept student's answers to inquiries, prompt students and label objects and information for students in the student's native language. Hart also recommended strategies including supplementing instruction with visuals; increasing wait time, using simple, clear and concise English, offering frequent summaries of instruction, checking for comprehension frequently, pre-teaching vocabulary, highlighting key vocabulary in a text, and using graphic organizers and priming.

Other researchers have described strategies for differentiating instruction and modifying curriculum in general and special education classrooms for ELL students with learning disabilities (Hoover \& Patton, 2005). They identified six curricular factors necessary to differentiate and adapt curriculum including the use of routine conversational social language, acknowledging that acculturation is a process and affects learning, challenging students to use higher-order thinking abilities, incorporating students' culture into teaching practices, scaffolding instruction upon existing knowledge and understanding how a student's culture impacts their learning. Hoover and Patton stated, "successful implementation and differentiation of curriculum and instruction for ELLs requires understanding and application of various cultural and linguistic factors" ( $p$. 235). 
Klingner and Soltero-Gonzalez (2009) reiterated the methods suggested by Hoover and Patton (2005) and described them as The Sheltered Instruction Observation Protocol model, a research-based model used in ELL programs to deliver instruction. They suggested that special educators could adopt this model when teaching ELL students with disabilities. The Sheltered Instruction Observation Protocol model includes the best practices used in ELL instruction including pre-teaching vocabulary, varying instruction modes, providing opportunity to use higher thinking, increasing response time for students and using graphic organizers and illustrations to supplement text. Almanza de Schonewise and Klingner (2012) advised the use of culturally familiar text when working on increasing reading comprehension for ELL students with learning disabilities. They also recommended strategies to build comprehension including using peer tutors, brainstorming, prediction, clarification, and summarization.

Numerous experts have suggested that the evidence-based interventions that are successful with ELL students could be incorporated into special educators teaching with support from the school district and collaboration between ELL and special education educators. The best practices reviewed provided a basis for the thematic analysis of the participant's descriptions of what supports, resources and strategies contributed to their ELL students' success.

\section{The Proposed Study}

Despite almost 50 years of disproportionality in special education and the development of major frameworks to explain the persistence of disproportionality, it is noteworthy that the voice and experiences of special educators themselves have not been 
included in the conversation. I proposed to address this gap by conducting a study to describe special education teachers' experiences teaching students currently or previously enrolled in an English language learner program who are receiving special education services by exploring teachers' views of what supports, resources and strategies contribute to student success and their views of the eligibility determination and referral process. To address this gap in the research, I conducted an exploratory descriptive qualitative study based on interviews with special educators about their perceptions and experiences while teaching these students, supports they received, their collaboration with ELL teachers, and their views of the eligibility determination and referral process. This literature review provided the foundation for the later analysis of the participants' responses.

\section{Review of Methodological Literature}

Qualitative research is often used to conduct discovery research and descriptive research in situations where little research has been conducted (Charmaz, 2006; Maxwell, 2005). In the context of this study the fact that the views and experiences of special educators regarding the education of ELL students placed in special education has not yet been gathered, interviews with special educators was a useful and appropriate first step of inquiry. Previous qualitative studies, such as Klingner and Harry's (2006) study of school professionals' participation in the pre-referral and referral process have yielded important findings for gaining a deeper understanding of disproportionality in the day to day decision making processes of school professionals. Prominent researchers in special education have described how qualitative studies in special education have revealed 
important social conditions, impacted policy, and led the way to new approaches that were then validated through quantitative research (Brantlinger, Jimenez, Klingner, Pugach, \& Richardson, 2005). Lastly, qualitative interview studies, such as the one conducted, reveal what seems to be the most salient or important in phenomena and can provide the needed direction for subsequent quantitative research, such as developing questions for survey research with a larger sample (Maxwell, 2005).

In the next chapter, the method used to address the research questions through educator interviews and thematic analysis is described. When analyzing educator responses it was possible that one or more of the frameworks proposed would explain the root causes of disproportionality that may have aligned with the educators' experiences with the assessment and referral process. The educators' descriptions of their teaching strategies and supports were examined in light of culturally responsive pedagogy and best practices recommended in the literature. 


\section{CHAPTER 3}

\section{METHOD}

\section{Introduction}

In this chapter, the research methodology used is described and the rationale for the methods selected is explained. The purpose of this study was to describe special education teachers' experiences teaching students currently or previously enrolled in an English language learner program who are receiving special education services by exploring teachers' views of what supports, resources and strategies contribute to student success and their views of the eligibility determination and referral process. I used a descriptive case study with a qualitative design conducting interviews to collect knowledge of special educators' experiences and perspectives. Nationally a discussion is taking place concerning the disproportionate number of ELL students who are being referred for special education evaluation (Strand \& Lindsay, 2009; Tedesco \& Franks, 2012; Wilkinson, Ortiz, Robertson, \& Kushner, 2006). As ELL students are placed in special education programs, special educators are being challenged to serve them and this study explored how they are meeting this challenge.

The qualitative method allowed me to use interviews to "uncover the meaning structures that participants use to organize their experiences and make sense of their worlds' (Hatch, 2002, p. 91). Hatch further explained that these units of meaning often are not be found by direct observation.

As a special educator myself, I am an emic, an insider to the profession who also is employed in the same school district as some of the participants. Special educators are 
honing their practice to include and accommodate ELL students and their insights interest me. On one hand, my emic status allowed me to gain the trust of the special educators selected to interview for the study. On the other hand, it could have been detrimental, in that they might have feared that I was an informer. My impression is that the participants felt confident that their confidentiality was secure.

\section{Research Method}

Qualitative research is a systemic approach to understanding qualities, or essential nature, of a phenomenon within a particular context. (Brantlinger et al., 2005, p. 195)

A qualitative method was selected for my research to allow for inquiry into the special educators' experiences by collecting data through the interview process and then analyzing this data for patterns and themes (Creswell, 2007). When reporting on their experiences, participants' unique voices emerged. The characteristics of the qualitative research method aligned with my interest in collecting the stories of special educators as they adjust to serve an increasing number of students currently or previously enrolled in an English language learner program who are receiving special education services. As the researcher, I was the key instrument in my collection of the data and had close interaction with my participants. The interview data were scrutinized for themes and patterns that illustrated the common experiences of my participants; these themes were then coded and categorized. From the data analysis, an understanding of the specific needs of special educators in this study was identified. A descriptive case study served my purpose. By collecting the in-depth stories of my participants, I believe they felt empowered as they reflected on their practice and shared their feelings, concerns, knowledge and experiences. 


\section{Participant Selection}

\section{Sampling and Sampling Procedures}

The standard quality indicators for qualitative research in special education defined by Brantlinger et al. (2005) were followed in the design of this study. In the area of sampling, this included the effective and purposeful selection of participants, a representative sample of the population to be studied, in this case, middle and high school special educators, and a commitment to confidentiality. Interview questions were carefully and clearly crafted for understanding, recorded digitally and transcribed verbatim deleting any identifying information. Purposeful and criterion sampling was used, however an insufficient number of participants were identified so snowball sampling was used to gain more participants (Brantlinger et al., 2005).

\section{Institutional Review Board}

Prior to proceeding with this study, approval was sought from Portland State University’s Institutional Review Board (IRB). After an IRB application for expedited/full review was submitted and reviewed by the Portland State University IRB Approval Committee, an IRB exemption letter was obtained. All material related to informed consent, confidentiality and risk was addressed through their approval process. Participants were assured of confidentiality.

\section{Purposeful Sampling}

In order to identify specific schools for the recruitment of potential participants, school demographic data was reviewed for each school in the selected school districts to find the top third of middle and high schools that serve a greatest number of both students 
with special education and ELL eligibilities. Review of the individual school demographic data was important to insure that ELL students were represented at the schools chosen. Criterion sampling was then used to identify the special educators for possible participation in the study.

\section{Criterion-Based Sampling}

In the initial stage of recruitment, purposive sampling was used to find a pool of potential participants from two school districts pool of special educators. Then criterion sampling was employed to identify specific educators eligible for participation. The targeted number of participants was 10 to 15 secondary special educators but only five participants met the criteria. I choose to interview teachers who were beyond the three year probationary period because I thought they would feel secure in their positions and therefore be more forthright in their responses.

Participants met the following criteria:

- Current certification in special education in the state of Oregon.

- Currently employed as a secondary special educator in a middle or high school in the district in Oregon

- Three years or more of employment as a special educator

- One-year minimum experience serving one or more students with an eligibility for special education and ELL and/or a student with an eligibility for special education who at one time in their K-12 education had an eligibility for English language services

\section{Snowball Sampling}

When participant recruitment began, participants identified other special educators that they felt might be interested in participating and they were screened to determine if they met the criteria (Merriam, 2009). Because the minimum of 10 
participants was not met by the researcher's recruitment methods, additional participants were gained through snowball sampling. In Chapter 4 a more detailed discussion of the results of recruitment is provided.

\section{Details of Recruitment Procedure}

Two school districts, one urban, the other suburban, in the state of Oregon with the highest and third highest number of ELL students in their students' population were chosen from which to recruit participants. The suburban school district had a total student enrollment of around 11,000 with seven middle and high schools. The urban school district had a total student enrollment of around 46,000 with 21 middle and high schools. A detailed information letter was sent by U.S. postal mail to all the special educators in each school (Appendix A). The letter included an explanation of the purpose of the study, criterion for participation, description of the interview process and assurance that the participant had the right to withdraw from the study at any time. A small gratuity was provided to participants who met the criteria in the form of their choice of a $\$ 10$ Starbucks or Fred Meyer gift card as an expression of appreciation. Participants responded by writing to me using my Portland State University email address.

Prior to the conducting the interview, a letter of informed consent was reviewed and signed by the researcher and signed with the initials of the participants (Appendix B). When making an informed choice to participate, prospective participants were told that the researcher is a peer and given assurance of confidentiality. In addition, they were given the guarantee that they have a right to refuse to answer any question or withdraw from the study at any time. 


\section{Procedures}

\section{Maintaining Data}

To insure confidentiality of the participants all identifying information including if they were a middle school or high school teacher, gender, their school's geographic location within the city limits (NE, SE, NW, SW) and school program affiliation was removed from the digital recording and then the transcripts were transcribed verbatim.

\section{Interviews}

Qualitative researchers use interviews to uncover the meaning that participants use to organize their experiences and make sense of their worlds. These meaning structures are often hidden from direct observation and taken for granted by participants, and qualitative interview techniques offer tools for bringing these meanings to the surface. (Hatch, 2002, p. 91)

The interviews took place after school hours and were recorded using a digital recorder lasting between one and half to three hours. Field notes were taken during the interviews. At the end of each interview, the researcher conducted member checking by summarizing the field notes and asking the participants to confirm that the notes accurately reflected their comments. Any revisions or additions from the participant were then recorded. The interviews took place in a location chosen by the participant that provided sufficient privacy and was conducive to recording.

\section{Instruments and Measures}

In order to evaluate the interview protocol prior to the study commencing, a tentative interview protocol was created and field-tested with two educators. Data from these interviews were not used in the final study and no questions were modified based on results of this field test. The educators were asked to give feedback on the clarity of the questions. Their feedback was used to decide not to modify the questions and 
established the projected time needed for the interviews. The educators were asked if the assurance of confidentiality was sufficient and they expressed that they were confident that their confidentiality was preserved.

As Creswell (1994) recommended, the interviews began with what he refers to as "grand tour" questions, open-ended questions followed by five to seven sub-questions to narrow the focus (Appendix C). Yin (2003) reminded qualitative researchers to remain willing to modify procedures and plans as the study unfolds by being flexible and to recognize when a participant's answer provides an unexpected opportunity. As an interviewer this researcher probed participants' responses when necessary to glean more detail. I found that using a conversational tone established trust. The use of interviews was suitable for this project and gave the participants the opportunity to share their experiences, perceptions and reflections on the resources and supports available to them as they teach students currently or previously enrolled in an English language learner program who are receiving special education services. Data analysis of the participants' responses enabled me to deconstruct their experiences and identify themes.

Once the study commenced and the first two transcripts were prepared and analyzed it became clear that no additional questions were needed.

\section{Role of the Researcher}

The research was conducted with some participants employed by the same school district in which I work as a special educator. My hope was that participants would enthusiastically embrace this research project and recognize the opportunity for their experiences to be heard and I believe they did. As a peer who was genuinely interested in 
their experience, my participants spoke frankly. I was aware that being a peer might be a disadvantage as I might be perceived as an informer but this did not appear to be the case. It was important to assure the participants that confidentiality would be maintained at all times during the study and thereafter.

In the introduction in Chapter 1, I shared my experience with a Somali Bantu student, Daod who was receiving ELL services. He had attended several different schools in the United States for two years when he was referred for a special education evaluation. Prior to his arrival he had no formal schooling while living in a refugee camp. Daod was given an intelligence test in English and found eligible for special education under the category of intellectual disability. Many researchers have determined that it is inappropriate to conduct measures of intelligence test in a language a student is not fluent in (Abedi, 2006; Cook-Morales et al., 2006). There are many factors that impact a refugee student's academic success upon arriving to the United States including acculturation and assimilation (McCardle et al., 2005).

Because of my experience with Daod, I wondered how special educators were teaching ELL students receiving special education services so therefore my overarching research question was how are special educators teaching students currently or previously enrolled in an English language learner program who are receiving special education services? Because there is a national discussion about the increase of ELL students in special education, surely school districts are preparing their special educators. The development of the research questions progressed naturally from my experience as a teacher (Appendix C). I knew my participants would need professional development, 
resources, strategies and collaboration to serve these students. My hope was that I would find special educators who were well prepared for the arrival of ELL students to special education and were provided sufficient resources to promote student success. I naively assumed this would be the case and that in my conclusion I would be discussing the models of best practice I encountered.

Several years passed while I contemplated these questions and conducted research into this issue when I became aware of another ELL student, Maryan, a teenage girl from Ethiopia, with a story similar to Daod's . She arrived in the United States with no formal schooling. Shortly after her school attendance began, a persistent effort on the part of the ELL department to have her tested for special education services began. The school psychologist resisted and it became a contentious issue between the ELL department and the school psychologist. This debate continued with the special education department lawyer advising the school psychologist to not test Maryan until she was in the country for two years. Despite the district lawyer's edict, the school psychologist was persistently challenged to test the student, by the ELL department. It was remarkable to watch from the sidelines.

These experiences were instrumental in my pursuing this topic and as I delved into more of the research it became evident that a group of researchers were discovering that nationally a disproportionate number of ELL students were being found eligible for special education services (Klingner et al., 2005; Ortiz et al., 2011).

Because my experiences are a clear source of bias, strategies were used to acknowledge and clarify researcher bias as the study was conducted including member 
checking and peer review. These strategies are described in more detail in the following section.

\section{Data Collection and Data Analysis}

\section{Data Collection}

Participants chose a location for the interviews in which they felt comfortable and safe, most interviews took place in coffee shops. The informed consent letter was reviewed with and signed by the participants prior to the interview process. Once interviews commenced they were digitally recorded and later transcribed with all identifying data deleted. At the end of the interview the participants were given a choice of a $\$ 10$ gift card from either Starbucks or Fred Meyer.

\section{Data Analysis}

The use of open-ended questions was intended to encourage participants to open up about their experiences. The participants' responses were analyzed by searching for patterns or themes (Creswell, 2007). Each verbatim comment from a participant that included one or more complete thoughts represented a unit of meaning from the transcript and was written on a post it note and placed on a chart with similar comments. The transcripts were reread many times to insure that all units of meaning related to established categories were noted. This method helped the researcher understand and explain the data. When classifying reoccurring ideas, themes emerged. As each new idea was identified, it was compared to existing ideas in the data (Gay \& Airasian, 2000). 


\section{Creditability and Trustworthiness}

The use of member checking and peer debriefing enhanced the credibility and trustworthiness of the study. Field notes were kept throughout the study.

\section{Member Checking}

Member checking occurred at two points within the study. Field notes were taken throughout each interview and reviewed afterwards with the participant to give them an opportunity to clarify any comments. Second, when interviews were transcribed and themes were identified, the researcher randomly selected two participants to review the findings, conclusions and interpretations (Hatch, 2002). We met and reviewed the data that was organized by question and theme. The participants in the member checking process expressed a sense of relief that their experiences were not unique though it saddened them that other special educators felt they were not able to adequately serve their ELL students currently or previously enrolled in an English language learner program who are receiving special education services. They were particularly interested to know that the other participants were veteran special educators as well.

\section{Peer Debriefing}

Throughout the duration of the study, each case was discussed with two educator peers after the transcripts were transcribed. As the data yielded emerging themes, they were asked to consider if my researcher bias was influencing the study and they determined that my interpretations were objective. 


\section{Conclusion}

Examining the experiences of special educators is important to learn from given the increase in students currently or previously enrolled in an English language learner program who are receiving special education services. By giving special educators an opportunity to share their stories, the researcher learned about their experiences, needs and views and was able to make recommendations discussed at length in Chapter 5. 


\section{CHAPTER 4}

\section{RESULTS/ANALYSIS}

\section{Introduction}

The purpose of this study was to describe special education teachers' experiences teaching students currently or previously enrolled in an English language learner program who are receiving special education services by exploring teachers' views of what supports, resources and strategies contribute to student success and their views of the eligibility determination and referral process. The overarching research question was how are special educators teaching students currently or previously enrolled in an English language learner program who are receiving special education services? The research questions I pursued were: How are special educators prepared to teach students with ELL and special education eligibilities? What resources are provided special educators teaching these students? What strategies do special educators find promote success for these students? How do special educators and ELL teachers collaborate? What are special educators' experiences with and impressions of the referral and placement process of ELL students into special education? What do special educators think about the idea that there is a disproportionate number of ELL students referred to special education?

It is important to examine special educators' experiences as to how best serve students currently or previously enrolled in the ELL program who are receiving special education services because nationally an increasing number of these students are found eligible for special education services (Artiles \& Trent, 1994; Klingner \& Harry, 2006; Maxwell \& Shah, 2012). The U.S. Department of Education, Institute of Education 
Sciences, National Center for Education Statistics (2013a) has reported that in the 20112012 school year, $10.5 \%$ of students in Oregon were enrolled in the ELL program. In the following section, the results of this study are described.

\section{Participant Selection}

Using purposeful, criterion and snowball sampling to identify participants, I proposed to interview 10 to 15 special educators from two school districts. When initially designing the study, I thought it would be fairly easy to find this number of participants. Unfortunately this was the naiveté of a novice researcher. Two school districts were chosen from which to seek participants based on state data that showed that these two school districts are two of four in the state with the highest number of students enrolled in the ELL program. I sent an information letter detailing the purpose of my study to the two special education directors of the school districts accompanied by a request for access to their email list of special educators. When two weeks passed with no response, another email was sent. I sent four emails over an eight period and received no response from the special education directors. I then sent information letters by U. S. postal mail directly to special educators at their schools in mid-May, seven weeks before the end of the school year. A total of 155 information letters were sent to special educators in the two school districts. In the one suburban school district, 53 letters were sent, two special educators responded and out of that number only one met the study criteria and was interviewed. In the urban school district, there was a larger pool of special educators from which to recruit and 102 letters were sent, seven special educators responded. One respondent did not meet the criteria and four decided they did not have time to 
participate. The two remaining respondents met the criteria and were interviewed. Three participants were recruited from both school districts through this method. I recruited two additional participants, one from each school district, through snowball sampling based on referrals from two of the participants.

\section{Participants' Characteristics}

The five participants came from a diverse set of schools from a wide geographic area within their school districts therefore none of them shared a supervisor. All of the participants were white and middle aged, four were female and one was male. The lack of racial and ethnic diversity was a disappointment and a limitation. I looked forward to learning if the experiences and perceptions of educators from varied backgrounds differed. All of the participants were veteran special educators having between 10 and 25 years experience, they represented career special educators, which are increasingly rare in special education. Billingsley (2004) reported that $40 \%$ of special educators leave the profession within the first three years of teaching and that nationally $98 \%$ of school districts report a shortage of special educators. The participants expressed a steadfast commitment to their students and profession.

Table 3

Recruitment of Study Participants

\begin{tabular}{lcccc}
\hline & Letters Sent & Responses & Vetted Participant & $\begin{array}{c}\text { Percentage } \\
\text { of Responses }\end{array}$ \\
\hline School district \#1 & 53 & 2 & 1 & $3 \%$ \\
School district \#2 & 102 & 7 & 2 & $6 \%$ \\
\hline
\end{tabular}




\section{Data Collection and Analysis}

The interviews were recorded on an Ipad using a recording app. The digital audio recording for the five interviews was sent to a transcription service. Each participant was assigned a number. During data collection I used two strategies to establish trustworthiness: (a) peer debriefing during data coding and theme development, and (b) member checks with participants. I met regularly with two teacher peers to discuss my progress, impressions and review transcripts. We consulted as to what themes were emerging and what coding method was most appropriate, we were all in agreement with the themes that emerged. Member checks took place with participants after each interview when reviewing field notes taken during the interview. After the transcripts were reviewed and categorized into themes, two participants were chosen at random and the researcher shared the findings. All participants expressed their comfort with the contents of the interviews and gratitude for listening to their experiences. Two participants were chosen at random to review findings, conclusions and interpretations.

I quickly reached a data saturation point. By the fifth interview, it was clear that the participants' responses were almost exactly the same in content for each participant; this was unexpected.

After studying coding methods, I chose in vivo coding because it allowed me to use the direct language of my participants. Each word or phrase of language found in the qualitative data record is a code and in vivo coding allowed me to "honor the participants voice" (Saldana, 2013, p. 91). The purpose of my study was to examine special educators' experiences therefore in vivo coding was an appropriate coding method. Upon 
receiving the written transcripts, they were closely read and reread numerous times to examine and compare interviews for similarities and differences and quotes were highlighted that stood out. I looked for unusual and useful quotes, reducing the data to themes as Creswell (1994) has advised.

\section{Presentation of Results}

Through an analysis of the data, five themes of deficiency in the following areas emerged: Professional Development, Resources, Instructional Strategies, Referral and Placement and Marginalization. Most of the themes that emerged aligned with the research questions and were consistent across all interviews. Though the five participants taught special education in a diverse set of schools, they reported very similar experiences regarding students currently or previously enrolled in the English language learner program who are receiving special education services. The most profound quotes were similar in content.

I embarked on this project hoping to find models of best practice but found instead, that the theme of marginalization, of both the students and their teachers, screamed out from the transcripts. School district administrators in both school districts repeatedly ignored teachers' requests for resources and support for ELL students receiving special education services, this indicates that the both the educators and their students were marginalized. To be marginalized is "to be placed in a position of marginal importance, influence, or power" (Random House Webster's unabridged dictionary, 2001, p. 1175). When essential resources are not distributed this leads to the marginalization of the participants and the students themselves. Because the special education 
administration has control over the distribution of resources, this creates a power imbalance contributing to the marginalization of the participants. It would be considered unthinkable to not provide curriculum to a fourth grade general education classroom, yet this was the common experience of all of the participants. They were consistently rebuked from both the ELL and special education departments when requesting curriculum and/or support required to teach students currently or previously enrolled in the ELL program who are receiving special education services. When asked what resources the special education department provided, participant \#5 said, "None. There were no services available," and participant \# 3 responded, "Zero.” All of the participants reported that there was no support provided in the form of professional development, resources, collaboration and materials for them to adequately serve these students. Saldana (2013) has recommended looking for "metaphors of opposition" (p. 118), these metaphors were found and led to the larger theme of marginalization, which pervaded each interview. "So, I mean, I don't expect an ideal world, but I think somebody would try to pay a little bit of attention that these kids, they do have needs," (participant \#3).

\section{Teacher Preparation}

The participants attended university programs to receive their teaching license with an endorsement in special education between 10 and 25 years ago. Participants reported that students who are currently or previously enrolled in the ELL program who are receiving special education services were not discussed in their special education programs, "No, not in my program," (participant \#1) and "I'm going to say no. I think when it's touched upon, it's in passing." (participant \#2). “ They don't even mention 
them.”, said participant \# 3. Participant \#4 stated, "I received no training on working with ELL students in special education in my teacher preparation program." When each participant began their teaching careers, they had students who were currently or previously enrolled in the ELL program on their caseloads and were not prepared to address their academic needs.

\section{Professional Development}

No professional development was offered by any of the participants' school districts specific to students currently or previously enrolled in the ELL program who are receiving special education services. When asked about professional development, participant \#1 said, “The only training I've received is recently...going to an institute on my own." This participant taught with the same school district for twenty years and recently attended training on her own, after feeling she was not prepared to meet the needs of these students.

One participant's school district offered a professional development workshop on special education which included a brief lecture on students currently or previously enrolled in the ELL program who are receiving special education, "Probably in a one day workshop, kind of sandwiched in, and it was probably a couple of hours at most. I mean it's been very miniscule, I've worked for this district since 1990." (participant \#5). Participant \#4 said, “ I'm getting a whole bunch of kids who are ELL and identified for special education services, I need more information." When participant \#5 knew ELL students would be added to her caseload the next school year, she attended a summer class at the local university, 
I took a class, a graduate level class, that was offered in the summer many years ago, and it was part of the endorsement program to get your ELL endorsement at that time, but it was titled ELL students and special ed services, so it was targeted for teachers and SLPs who would be working with students who would be identified as ELL and also have special education needs, and so we were looking at the process and how do you identify, what do you sort out as cultural/language differences versus testing, how do you test, how do you get a representative of what the students' skills are, what happens when they're dual language, what the acquisition is, and what would be the best approach to use with these students.

In the 16 years of their teaching career, one of the participants (\#4) never received professional development on students currently or previously enrolled in the ELL program who are receiving special education even though their school district had a large influx of this student population over the last decade, as indicated by state educational data. "I needed guidance and support from the district yet there was none," and "The district saw the population change from primarily white middle class students to a varied and diverse student body but the PD did not keep up with the changing needs of the students and teachers," said participant \#4. This participant listed the lack of professional development, resources, support and collaboration as the reasons for planning to retire early within the next school year.

As both of the school districts experienced an increase in the population of students enrolled in the ELL program, more and more of these students were being referred to special education. The two school districts did not respond to the influx of these students by offering relevant professional development to address their specific academic needs. These students present a unique set of needs and the participants were ill prepared to address them. As participant \#1 said, "Our low achieving ELLs are not being served well by what I am doing," and "I'm feeling torn about it-do you know what I mean? Like where, what, what's the best place for them?" 


\section{Resources}

Every participant expressed frustration with the lack of resources provided from the special education department. They felt that this contributed to their inability to adequately address the needs of students currently or previously enrolled in the ELL program who were receiving special education services, "It's a very unique population and so what we have for special ed doesn't really apply," (participant \#2). "Frankly, the district doesn't care," said participant \#3. None of the participants shared a supervisor. Each participant expressed that they were persistent in their requests to their special education supervisor for materials, participant \#2 said, "The year was spent trying to get some curriculum." Participant \#1 stated, "They don't give us curriculum," and "There was no budget." None of the participants were successful in obtaining material from either their special education department or ELL colleagues. They also were unsuccessful in obtaining resources in the form of consultation, as participant \#3 said,

We had to be able to be very creative because we have no support system. The stuff we did - created ourselves. Because we have to tailor make everything we do to our student population.

And so, um, that's been the interesting part. I think that if there were a framework, so at least we knew we were deviating from it [laughs] instead of kind of - we - there's no guideline on would a student have both an ELL English class and a special ed English class. (participant \#2)

All of the participants expressed frustration and though the sample was small, it is interesting that they all had the same experience. It is disconcerting that the participants were unable to obtain materials necessary to address the basic academic needs of their students currently or previously enrolled in the ELL program who were receiving special education services. The participants' persistence was met with silence, they were simply 
ignored and this led them to feel that these students are not valued thus leading to the theme of marginalization. When asked what resources the special education department provided, participant \#3 flatly stated, "Zero."

\section{Collaboration}

The combined work experience of the participants equaled more than 100 years in special education. The lack of collaboration they experienced was unprecedented in their teaching careers. Each participant described a lack of collaboration between themselves and the building ELL teacher. They were unable to obtain resources or guidance from the special education department and turned to their building colleague, the ELL teacher for professional collaboration, to no avail. One of the participants consistently met resistance to collaboration with the building ELL teacher. This same ELL teacher consistently gave the ELL students who were also receiving special education services, grades of D and Fs in their English language development classes, "My students were getting Ds and Fs in ELL, so that told me that partly they weren't modifying their materials enough to meet them where they were," (participant \#2). Participant \#2 expressed her interest in collaborating on implementing differential instruction in the ELL classroom, the ELL teacher declined, “ The ELL teacher I work with the most was not very open to collaborating. I couldn't get her to an IEP meeting." Although all of the participants pursued a collaborative relationship with the ELL teacher, only one participant had a relationship with the ELL teacher in their building,

Um, and I, I would say at our school, I would say XXXX is super available, but I think that, I think we could do a better job about making sure she's, you know, really at the meetings, because sometimes she is-. Sometimes she is, sometimes she's not, you know? (participant \#1) 
Participant \#3 had a particularly negative experience with both the ELL

department and the building ELL teacher. When asked about collaboration with the ELL department, they stated,

We asked for the ELL person, uh, at school site. We contacted the ELL Department. Um, it took them almost three - two and a half-almost a third week of - of school, now we have only a week and a half of school left for them to come out, send an interpreter just to interpret the conversation with the parents about - asking questions about the student so we could do, uh, some testing on it. As far as the ELL Department is concerned, they said that they had nothing to give us 'cause he-because he was in special ed.

This unfortunate experience impacted this participant's ability to serve their student who had no knowledge of English.

In three of the schools where participants were employed, all students were removed from the ELL program automatically upon receiving an eligibility for special education. Formal English language development instruction ceased once the students were placed in special education. This occurred across both of the school districts in spite of the fact that the policy of the Oregon department of education is to retain ELL services for all students enrolled in the ELL program after they are found eligible for special education services (Scott, Boynton Hauerwas, \& Brown, 2014). In one of the schools, the ELL teacher was instructed by their ELL supervisor to drop ELL services immediately after the special education eligibility meeting and promptly did so without following their own ELL program process. Participant \#4 reported that, "It was policy at my school to remove ELL students from the ELL program when they became eligible for special ed.,", thereafter "The ELL teacher made it known she was unavailable."

Each participant also taught students who were currently enrolled in the ELL and special education programs. When the ELL student receiving special education services 
remained enrolled in the ELL program, at some schools, there was reluctance on the part of the ELL teacher to serve the dual identified students. There was a lack of communication between departments. Participant \#1 reported, "The ELL teacher and I never really talk about what she’s doing.” And participant \#2 said, “There's no guidance on would a student have both an ELL class and a special education class." When asked if their ELL students attended English language development classes in the ELL program, participant \#2 also replied,

Some of them did. There was a lot of confusion with the counselors and so we spent the whole year trying to sort out students' schedules. We have caseloads of 35 to 40 and so it took to the end of the year to even realize that some students were double or triple served or underserved.

Participant \#5 elaborated,

That's kind of a touchy issue, because there are ELL services identified for these students, but depending on who the ELL staff was, often they would approach the parents and get them to sign off and then remove them from ELL. They did not "meet the minimum required score to exit" because the ELL program determined they were not making adequate progress and that it must be because of their disability, and so then their services would be exit. Some students either the ELL department really liked a lot or they couldn't get a parent to come in or they couldn't figure out how to explain it, have continued to receive both services.

All of the participants reported that they always invited the ELL teacher to the IEP meetings of students who currently or previously were enrolled in the ELL program, even if the ELL teacher was not serving the student. Because of their knowledge of language acquisition, the ELL teacher's expertise is valuable when discussing the needs of students as related to language acquisition. "The ELL teacher I work with the most was not open to collaborating. I couldn't get her to an IEP meeting," stated participant \#2. 
ELL teachers generally did not consider themselves resources to the participants especially for students who were exited from the ELL program upon becoming eligible for special education services. They did not monitor their former students.

We asked for a TOSA, somebody to come out or just send somebody from the ELL Department to work with this kid for one- a couple hours a day for the first two days to get him acclimated. It never happened. (participant \#3)

When this particular student remained enrolled in the ELL program after receiving an eligibility for special education services, there was confusion as to who was responsible for providing English language instruction.

The lack of resources and collaboration was very frustrating to the participants. The question of who was responsible for completing required tasks was unclear. In one situation, participant \#3 assumed the ELL teacher would request the language interpreter for an IEP meeting and the ELL teacher assumed the special education teacher would make the request. This confusion delayed the IEP meeting, "We didn't get that interpreter for almost three weeks," stated participant \#3. This particular IEP meeting was considered urgent by participant \#3 because the student arrived in their special education classroom with no school district paperwork. The student's parents did not understand why he was recently removed from the ELL program and placed in special education as they had not been included in any part of the process. They were not fluent in English and were distressed; no one at the school could explain how and why the student was placed in special education.

Because the participants did not have any training or professional development in delivering English language development, they struggled to meet the needs of their students who are previously were enrolled in the ELL program. The participants 
persistently requested collaboration with building ELL teachers and/or resources from them to build upon previous ELL instruction and were consistently denied materials or consultation. ELL teachers are highly trained in language acquisition and know the sequence by which language is learned (Stromquist, 2012). The lack of support from the ELL teachers within their buildings was matched by the lack of support from the special education department and over time led the participants to feel isolated when trying to best serve students who currently or previously were enrolled in the ELL program who were receiving special education services.

\section{Instructional Strategies}

The participants each reported that they believed that the need for instruction in English language vocabulary was paramount.

Almost always we have to do an extended vocabulary, because their vocabulary isn't high enough even to meet the other students who are of similar ability because they haven't developed that level of vocabulary or that level of comprehension at the same rate as you would expect a gen ed student who didn't have a language disability or a Sp Ed student who didn't have a language impact, so no, I spend a lot of time developing vocabulary, I have to look at sentence structure, because if they're still speaking their native language the majority of their day, they're still thinking in that language, and so when you start to read like a written piece, it's very disjointed, depending on their native language, so then you have to look at how to restructure the writing so it meets a more standard convention for English, so it takes more time, more energy basically. (participant \#5)

There was uncertainty among all participants as to how to provide English vocabulary instruction, having not been trained to do so. “There's a lot vocabulary wise they don't have, and so that really impacts their comprehension," (participant \#1). The participants saw this as the greatest area of need and sometimes the sole reason the ELL student had been referred to special education. Participant \#2 stated, “They didn’t know what basic 
words meant and as they got more comfortable with me and would admit that, they'd say what is that word and I'd think oh, you don't know . . . the basics of English language, of course." "Their English language vocabulary was limited," stated participant \#4 and they felt that, "There is an incorrect assumption about ELL students grasp of the English vocabulary and this contributes to their referral to SPED."

Teaching English language acquisition is a skill taught in university programs as part of the requirements for licensure for an ELL endorsement. Special education teacher training programs do not cover this skill. The participants floundered when trying to address the need to build vocabulary with their ELL students, as participant \#3 said, "We had to be very creative because we have no support system." The participants proved to be resourceful and created their own materials, again participant \# 3 said, "We have to tailor make everything we do to our student population." The participants were creative in providing support to the students to build their English language vocabulary using visuals, concrete objects and an Ipad.

I mean, they're - but in terms of strategies ... when XXX and were working, my student teacher and I were working together . . . I have, you know, with iPads, and so I really try to, as I see they don't know vocabulary, I try to pull up pictures on the iPad to, to really anchor that, you know, that word to the picture for them, because even just talking about it doesn't always work." (participant \#2)

Participant \#3 said, "The stuff we did, we created ourselves." None of the participants were supplied with materials to teach English language acquisition from either the special education or ELL departments. The lack of collaboration between the departments and lack of resources was very frustrating for the participants and again led to my conclusion that both the participants and their students are marginalized. "The fact 
that he's in special ed, I mean, you know quite frankly we're the bastards of education." (participant \#3).

\section{Referral and Placement}

Every participant stressed that they believed the students who were currently or previously enrolled in the ELL program who were receiving special education services primarily lacked English vocabulary. Some of the participants felt that the special education eligibility assigned to the student was inaccurate, "There were students who were identified as intellectually disabled that I thought just had a mild learning disability, so, and performed far higher than I expected them to," and "I think the correct eligibility is a huge issue," (participant \#2). They elaborated,

I mean, my gut tells me that that's because, um, the students aren't proficient enough to do well in gen ed courses and so they decide that they are going to test them using whatever tests that probably are not very appropriate for ELL students and qualify them. I mean, I do think it's tricky to determine. You have to test them in their native language, right? (participant \#2)

Participant \#3 said, "Well, I think that sometimes, uh, people don't understand that the language barrier, or if it is intellectual, I mean it's obvious if a kid's got CP. He's got CP." Participants shared reasons that an ELL student may be referred to the building screening committee (BSC), "ELL students were funneled into SPED because they were not learning at same pace as their peers so the gen ed or ELL teacher pressed for a special education referral," said participant \#4.

When a student who is a non-native English speaker is assessed for special education with testing instruments normed on white middle class students, they are not being compared to their true peers. Comparing a student to a true peer, a student who has a similar cultural and linguistic background, would be more appropriate. Participant \#5 
expressed, "The ELL teacher is usually the person who seems to spearhead it based on their experience of English language skill," when asked about referral for special education evaluation. When asked about the referral process, participant \#1 explained,

They're getting ELL services already, so it's kinda like what's the next step. Refer them to special education because the teacher generally cares about the kid.

They know that they need something more than what the large classroom environment can provide for them, you know?

And I feel torn there 'cause I think that is true. I think they do need additional support in being able to navigate and understand, you know, um-it's-yeah, so that's, that's my opinion about why it happens.

Most of the participants had limited experience with the process that would conclude with an evaluation for special education. The building screening committee (BSC) for a student currently enrolled in the ELL program is required to consist of a general education, special education and ELL teacher, speech language pathologist, school psychologist, building administrator in charge of special education and ELL, parents and a language interpreter. A general education teacher or ELL teacher can refer a student to the BSC when there are concerns about their academic progress. The team suggests interventions and data collection commences as the interventions are implemented for up to six weeks. The BSC team then reconvenes to evaluate the data and add additional interventions if deemed necessary. The process repeats itself and they reconvene again and decide if an evaluation for special education is warranted. Parents then give written permission to test for special education.

The school psychologist conducts an assessment written in English which results in a number indicating the student's intelligence quotient; a language interpreter is required by the guidelines distributed by the Oregon Department of Education to translate 
the assessment as it is given. The special education teacher conducts an academic assessment accompanied by a language interpreter. All of the tests are written in English and contain content that is typical of white middle class culture and normed on white middle class students. Participant \#4 reported that, "The ELL students in my building were tested in English." The team reconvenes again to discuss the results and determines if the student fits the criteria to be eligible for special education. The team reviews the student's assessment results and determines if the criteria is met for eligibility for special education services within a disability category. It is a laborious multi step process which the state of Oregon expects BSC teams to follow. From the participants' reports it became clear that their building BSC teams did not follow the guidance provided by the state.

Only one participant (\#5) had attended a building screening committee meeting and understood how the process of referral and placement to special education was supposed to proceed though when referring to students currently enrolled in the ELL program, they said, ". . . those are looked at differently and they are fast tracked usually." Four of the five participants reported that in their experience, once the student currently enrolled in the ELL program was tested and found eligible for special education services, they were dropped from the ELL program. Once the student was exited and placed in special education, all of the participants reported that no documents from the ELL department summarizing current skills followed the student. None of the participants had any knowledge of the interventions implemented as a result of the BSC meetings. The participants expressed frustration that resources did not follow a student 
who was previously enrolled in the ELL program once they received an eligibility for special education services, participant \#3 expressed,

There's no sense of urgency because they don't have to deal with it in the first place, and the second part of the component is that when you make a referral that people ought to provide resources without saying, 'Well, we can't afford that'. So, I mean, I don't expect the ideal world, but I think that somebody would try to pay a little bit of attention that these kids do have needs.

The participants had a limited understanding of the BSC's function and were not included in the process, as the state requires. The participants all reported that they did not have any knowledge of their students' prior instruction or skill development while enrolled in the ELL program. When discussing the referral and placement of students enrolled in the ELL program, participant \#4 stated, "SPED is a dumping ground."

\section{Data Analysis}

Creswell (2007) suggested looking for surprising information, something one did not expect to find. The purpose of this study was to describe special education teachers' experiences teaching students currently or previously enrolled in an English language learner program who are receiving special education services by exploring teachers' views of what supports, resources and strategies contribute to student success and their views of the eligibility determination and referral process. The participants repeatedly reported a lack of resources including professional development, curriculum and staff support from the special education department and strategies and collaboration from the ELL department. The lack of resources permeated throughout every interview and was an unexpected and alarming finding.

A consistent lack of resources and support over a period of years, was reported by all of the participants, this lead to my conclusion that the participants and their 
students are marginalized. By not providing even minimal resources, the school districts are rendering the participants powerless to serve this population of students. By repeatedly ignoring the requests for resources, they imply that these students are not worthy of the materials, resources and support that are mandatory for all other students in the districts. Not investing in resources for general education students would be considered an outrage and thoroughly unacceptable. It is unheard of, to not supply a general education teacher with curriculum to address the needs of students in a general education classroom. Yet all of the participants described persistent attempts, over a period of years, to secure suitable curriculum for students currently or previously enrolled in the ELL program who are receiving special education services. Stromquist (2012) referred to the marginalization of CLD students when placed in special education as a form of tracking by denying students opportunities and access to resources available in general education.

\section{Limitations of Study}

When planning the research study, I assumed the two school districts would give me access to their email group lists of special educators from which I would recruit participants. After two months of repeated requests, both of the school districts did not respond. This delayed the timeline I projected and it became necessary to contact potential participants by an alternative method. I sent an information letters to each special educator by U.S. postal mail. By the time I sent out the letters, the end of the school year was fast approaching, and I know, as a teacher myself, that is a very busy time of the year. I believe this timing may have influenced the small number of responses 
I received and limited my number of participants. Four of the respondents decided they did not have time to participate as summer was fast approaching. Because I contacted participants by U.S. postal mail, some potential participants questioned my legitimacy and wanted to know why I did not recruit through more official channels such as the school district. The findings represent the experience of five special educators. The results of this study cannot be generalized due to the small number of participants warranting further research on this topic.

Another limitation of this study is that participants' responses could have been influenced by the fact that as the researcher I am also an educator peer working in the same school district. The participants might have been intimidated and/or fearful of my revealing their thoughts, despite the reassurance of confidentiality. When discussing the informed consent letter, I assured the participants of confidentiality. I believe based on their responses, they felt comfortable answering all of the questions and trusted that their responses would not be shared inappropriately.

All of the participants were white; this is a major limitation to this study. The responses to the questions posed were viewed through the through the lens of the dominant white culture. In the state of Oregon for the school year 2014-2015, 91.5\% of the teachers are white (Oregon Department of Education, 2016). Participants of color and educators with bilingual/bicultural backgrounds would have brought valuable insight to this project.

And lastly, a major limitation of this study is that I am a novice researcher. While interviewing the participants I realized that interviewing is a skill that requires practice. 
The act of interviewing looks effortless but I experienced many awkward moments when conducting my interviews. As I reviewed my transcripts, it became clear, that numerous times a topic could have been pursued further by asking more follow up questions. When participants went off on tangents, I could have steered them back to the topic at hand and been altogether more graceful. There were many times during the interviews that I stumbled. Though I put forth great effort, after examination of my data I see where I faltered, this is the limitation of a novice researcher that may have affected the amount of data collected.

As similar themes emerged during the interviews, recommendations in response to those themes became clear. Recommendations are discussed at some length in the next chapter. 


\section{CHAPTER 5 \\ DISCUSSION/CONCLUSION}

Introduction

In this final chapter, I review the purpose of my study and discuss the results as related to the theoretical frameworks outlined in Chapter 2 as well as offer recommendations to address the deficiencies revealed in my study.

The purpose of this study was to describe special education teachers' experiences teaching students currently or previously enrolled in an English language learner program who are receiving special education services by exploring teachers' views of what supports, resources and strategies contribute to student success and their views of the eligibility determination and referral process.

\section{Synthesis of Findings}

Special education teachers from two school districts were recruited to participate in the study. After screening the respondents, five participants met the criteria. When analyzing the participants' responses, the theme of deficiency in the following areas emerged: professional development, resources, instructional strategies, and referral and placement.

The marginalization of both the students and participants was an overarching theme permeating each interview due to the consistent reports of the lack of resources provided. Artiles (2003, p. 175) has argued that special education "is a historically segregated system that has been used to marginalize students deemed problematic". The participants reported that it was difficult to meet the needs of students currently or 
previously enrolled in the ELL program who are receiving special education services. when they possessed no relevant materials. When basic educational necessities are not supplied, the message sent to both the participants and their students is that they are not valued. Artiles (2003), one of the predominate researchers focusing on this population of students wrote,

Individuals and groups who possess cultural capital have advantages over marginalized or oppressed people with educational or labor opportunities, since educational systems are built on the knowledge and values of dominant groups. (p. 169)

This statement is relevant when considering the lack of resources and support the participants faced when striving to meet the academic needs of these students. The participants were unable to prepare their students to compete for opportunities in educational settings and the labor market. Artiles reminded us that when discussing special education it is important to look at the power deferential. When the two school districts in which the participants were employed made the deliberate choice over decades to not provide them with resources equivalent to those provided to the educators of general education students, this contributes to these students being relegated to low paying unskilled job positions as adults.

Blanchett (2006) has defined four sub systems of education operating within the public school system. They represent a hierarchy of resources and support that developed as a result of structural racism. At the top of the hierarchy is the first subsystem of general education, designed to serve white students. In this sub system the students have access to the latest technology and are offered advanced placement classes taught by the most highly educated and qualified educators. Next in the hierarchy is the second 
subsystem Blanchett has identified as general education for students of color in schools that predominately serve students of color. In this subsystem there is a high turnover of educators who most often have the least amount of experience and students have limited access to technology. Blanchett described the third subsystem as education for white students with disabilities. These students are educated in general education with multiple services and supports including occupational and physical therapy, assistive technology, one on one adult support and access to technology suited specifically to their individual needs. The fourth subsystem is segregated special education placement for students of color with disabilities. In this final subsystem of the hierarchy, students receive minimum services and staff support and limited resources and access to technology. The experiences of the participants in this study fit into this lowest sub system in Blanchett's hierarchy. Blanchett's description of the hierarchy of education describes the marginalization experienced by my study participants. The professional decisions that can occur within a stratified system can result in differential treatment of some groups within the system (Sullivan \& Artiles, 2011).

These social systems are dynamic, hierarchical, and socially constructed in racial ideology (or racism) that influences the behaviors of individuals within the system. (Sullivan \& Artiles, 2011, p. 1529)

\section{Theoretical Frameworks}

Four predominant frameworks were discussed in Chapter 2 as related to the experiences of students currently or previously enrolled in the ELL program who are receiving special education services; culturally deficit thinking, socio demographic factors, socio cultural factors, and structural inequity theory. These frameworks were 
described because I proposed that one or more would emerge as the foundation for the thematic analysis of the participants' interview responses.

Structural inequity theory emerged as the explanation for the marginalization of both the students currently or previously enrolled in the ELL program who are receiving special education services and their teachers. Structural inequity theory attributes marginalization to institutional or structural racism that is deeply embedded within the educational system. This theoretical tool is important not only because it provides an explanation for my findings but also because it allows us to understand how a pattern of disproportionality and differential distribution of resources and supports in special education persists and how this results in the marginalization of these students and their teachers, as experienced by my participants.

Theoretical tools provide a powerful means of understanding the roots of this perplexing problem and offer a critical lens for understanding how supposedly equity-minded policies, such as special education law, becomes a means for perpetuating racial inequity, and offer a means of conceptualizing the factors that either foster or impede positive change. (Sullivan \& Artiles, 2011, p. 1584)

Despite my participants' efforts to address the specific needs of their students, a change in the distribution of resources will require systematic efforts. Later in this chapter, I make recommendations to respond to the deficiencies in professional development, resources, instructional strategies, and referral and assessmen.

\section{Structural Inequity Theory}

Racial and class inequity are reproduced over time through institutional and individuals action and decisions that maintain status quo at the expense of the less privileged group. (Skiba et al., 2006, p. 1426)

Sullivan and Artiles (2011) explained that structural inequity theory applies when a systematic bias is demonstrated by a patterned and differential distribution of resources, 
life chances and costs/benefits among groups of the population that result in structural inequities. Structural or institutional racism is defined by Bonilla-Silva (1996) as having the following characteristics; it is covert, embedded in normal operations, avoids direct racial terminology and is invisible to most white persons. When professional decisions take place in this system one will observe differential treatment among racial or ethnic groups. The reports of the participants in this study demonstrate that they were dealing with the consequences of a pattern of administrative decisions that were made over a period of years to not distribute the resources necessary to meet the needs of students currently or previously enrolled in the ELL program who are receiving special education services. The differential distribution of resources occurred repeatedly across two school districts by both ELL and special education school district administrators. The impact of this decision is profound, by not providing resources to meet the academic needs of these students, they were denied participation in opportunities afforded their same age peers in general education and access to the general education curriculum, creating a biased outcome. Biased racial outcomes associated with policies and practices are the result of structural inequity. Historically special education has been used to perpetuate the marginalization of students from minority racial/ethnic groups or limit their access to general education peers and curricula (Artiles \& Bal, 2008). Structural inequity theory aligns with the results of my study, as all of the participants reported the lack of resources appropriate to serve their student. The participants repeatedly over time requested support, which was never provided, thereby leading to the marginalization of both the participants and students. 
Anyon (2009) examined the structure of education through the lens of sociology postulating that the ways of learning of the dominant group are viewed as the norm and a student who differs from that, is viewed as disordered. They proposed that the process of identifying students with learning disabilities serves to support and reproduce social inequality and maintain the status quo. When Anyon looked at the special education eligibility category of severe learning disability from a structural perspective, they observed how it reflected broader social inequality and stratified expectations of student's future roles in the labor market. The participants in my study all agreed they were not able to adequately serve their students due to a lack of resources and support. Their students were not being prepared to competitively participate in the job market, lacking basic skills such as functional math and reading. The job prospects for their students are bound to be limited to unskilled low paying job positions with little hope of promotion. By not providing essential skills to students currently or previously enrolled in the ELL program who are receiving special education services, they are delegated to lowest level of the economic ladder in jobs where they are vulnerable to exploitation.

\section{Implications for Practice}

Given what I found, it is important that I present a discussion and then recommendations to address deficiencies in the areas of professional development, resources, instructional strategies, and referral and assessment for students currently or previously enrolled in an ELL program who are receiving special education services. In the following sections, research-based recommendations in these areas are described that address the marginalization of both the participants and their students. The responses 
from the participants overwhelmingly indicated that a lack of support in these areas was responsible for them struggling to meet the needs of these students.

Burr, Haas, and Ferriere (2015) worked with the National Center for Education Evaluation and Regional Assistance and reviewed academic articles about students with dual eligibility for ELL and special education services as well as state policies regarding these students in the 20 states with the highest number of ELL students including Oregon. In July 2015, they published a report of their findings and made recommendations in the areas of professional development and referral and placement on how to best address the needs of these students. They suggested using strategies such as response to intervention and child study teams prior to initiating a referral to special education (Burr et al.). When the decision is made to evaluate an ELL student for special education, school teams should use multiple forms of data to determine the eligibility for special education and thoroughly investigate and deliberate between true learning disability and issues related to language acquisition. Their report stressed the importance of involving parents by providing a language interpreter and translating documents into their native language. And lastly, they recommended that school districts develop policy guidelines and data tracking systems and provide professional development specifically addressing the unique issues ELL students face (Burr et al.). In the following section, I will explain in more detail the research-based recommendations made by the Burr et al., and other investigators. 


\section{Professional Development}

\section{Pre service Training}

There is a need to educate pre-service teachers about state standards in addition to teaching content and how to present it to students. Kolano, Davila, LaChance, and Coffey (2013) surveyed 157 teachers to determine how much training they received in their pre service teaching program on working with CLD students including students receiving English language service, $88 \%$ reported that they received no pre-service training from their university program specific to these students. Chu (2011) interviewed 31 special educators working with CLD students and found that most reported they did not have any classes during pre service training at the university level that addressed working with these students. Over a 5-year period, the school district they were employed by, saw a significant increase of these students yet no professional development was offered. This aligns with the results found in my study, $100 \%$ of my participants reported not receiving pre service training specifically addressing the needs of CLD students, including ELL students in their university programs. Kolano et al. (2013) found that when their study participants began their professional careers as teachers, they were provided less than two hours of professional development on working with ELL and CLD students.

Chu (2011) concluded that pre-service teacher programs in special education need to incorporate extensive training in how to successfully address the needs of CLD students, including ELL students. When participating in the required practicum experiences in the field, pre service teachers could be expected to partake in experiential 
learning with students from cultures dissimilar to their own to increase their knowledge of cultural differences. Immersion in an unfamiliar cultural, social and linguistic setting will led to greater understanding by challenging preexisting beliefs and assumptions (Kolano et al., 2013).

Numerous researchers have examined professional development offered in university pre service teaching programs and concluded that the pre service training for teachers insufficiently prepares them to work with CLD students, including students currently or previously enrolled in an ELL programs who are receiving special education services (Chu, 2011; Kolano et al., 2013). In my research I found similar results, my participants all reported a lack of pre service training addressing these students.

\section{School-Based Professional Development}

Kose and Lim (2010) conducted a survey investigating the relationship between transformative professional development and teaching practices. They proposed that transformative professional development is necessary to promote culturally relevant teaching and will help educators to incorporate and understand the cultural nuances presented by students of all cultural groups. Desimone (2009) maintained that transformative professional development includes a set of core features; co-teaching, mentoring and reflecting on lessons on line with peers and in-group discussions. They further explained that "there is research consensus to support the use of this core set of features" (Desimone, p. 181) in professional development. High quality professional development can be transformative, incorporating teacher knowledge while providing tools to support changes to support all students (Desimone, 2009; Kose \& Lim, 2010). 
Rinaldi and Samson (2008) have outlined topics for professional development that specifically address ELL students aimed at reducing the number of these students who are referred for special education evaluation (see Figure 2).

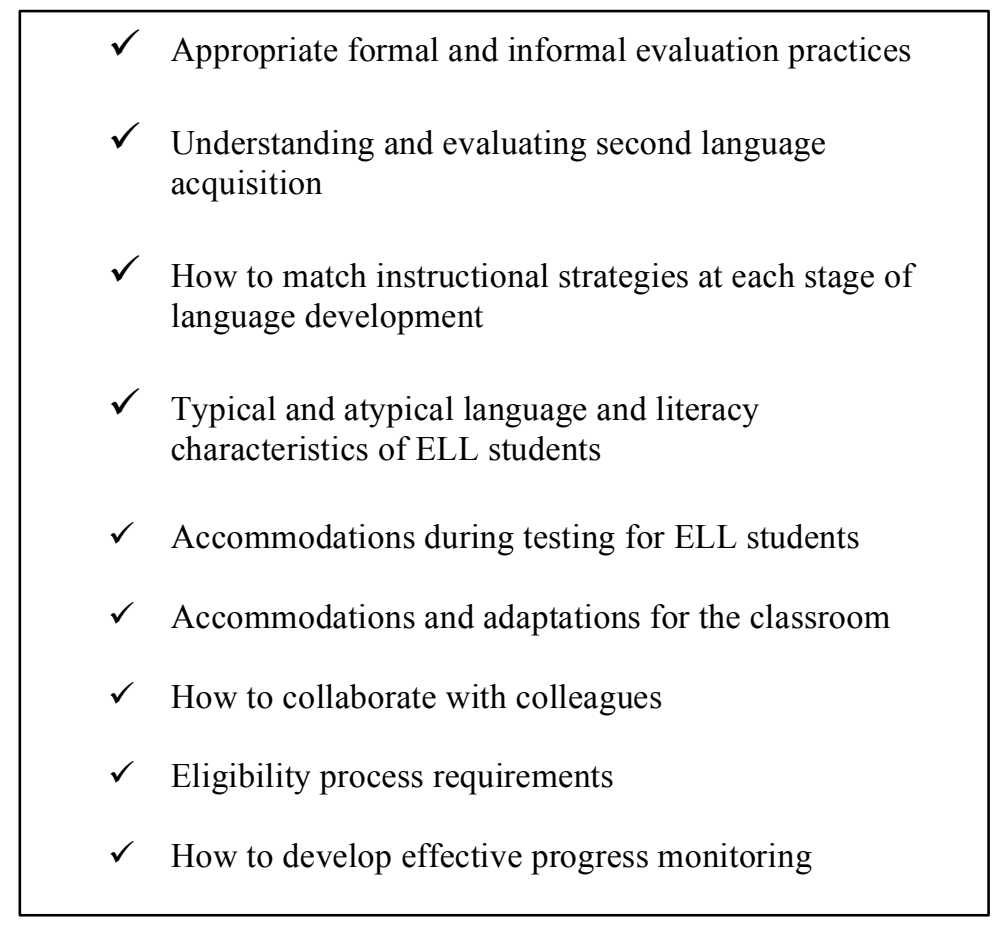

Figure 2. Professional development topics. Adapted from "English Language Learners and Response to Intervention: Referral Considerations," by C. Rinaldi and J. F. Samson, 2008, TEACHING Exceptional Children, 40(5), p. 13.

High quality professional development should have a strong content focus, provide concrete and active learning opportunities as well as collective participation and collaboration with peers (Dingle, Brownell, Leko, Boardman, \& Haager, 2011). Completing an action plan at the end of the professional development session gives an educator a concrete plan to follow and report on at a later date. It is important to recognize the knowledge and skills educators possess and provide educators opportunities to interact with each other (Dingle et al.). Kozleski and Smith (2009) reported that the content presented should directly relate to the educators' practice to increase their 
knowledge and skills and provide tools to support changes in practice. By offering monthly follow up and on-line learning communities, teachers have the support to align their practice with new strategies. Dingle et al. recommended reconvening after 6 months to report experiences about the implementation of new strategies and then problem solve any difficulties. All of the suggestions described above can be integrated into professional development addressing the needs of students currently or previously enrolled in an ELL program who are receiving special education services.

In a report Burr et al., (2015) conducted with the National Center for Education Evaluation and Regional Assistance, they defined issues critical to address when providing professional development for pre service teachers and practicing educators serving students currently or previously enrolled in an ELL program who are receiving special education services (see Table 4).

Table 4

Critical Issues to Address in Professional Development

- Understanding of second-language acquisition and learning disabilities (and their intersection)

- Ways that cultural background may influence behavior

- How best to communicate and interact with parents

- Early intervention strategies for ELL students who are struggling with reading and math

- Classroom management skills

- Eligibility determination for both second language and special education services

NOTE: Adapted from "Identifying and Supporting English Language Learner Students With Learning Disabilities: Key issues in Literature and Practice," by E. Burr, E. Haas, and K. Ferriere, 2015, U.S. Department of Education, Institute of Education Sciences, National Center for Education Evaluation and Regional Assistance. 
In this section research based recommendations were offered in the following areas; pre service training, guidelines for school based professional development and professional development specifically to addressing the needs of CLD students, including students currently or previously enrolled in an ELL program who are receiving special education services. These recommendations were offered in response to the participants' reports of the lack of professional development they received both as a pre service teachers and practicing educators.

\section{Instructional Strategies}

\section{Introduction}

The participants in this study overwhelmingly voiced a lack of knowledge of appropriate instructional strategies to address the specific needs of their students currently or previously enrolled in an ELL program who are receiving special education services. A large body of research has proposed that culturally responsive teaching (CRT) will increase the success of CLD students including the students of interest in this study, this research is discussed in the following section (Gay, 1993).

\section{Culturally Responsive Teaching}

Students currently or previously enrolled in an ELL program who are receiving special education services have a unique set of needs, as CLD students it is important that the professionals working with them are knowledgeable about culturally responsive teaching (Gay, 1993). None of the participants in the study reported having any professional development in this area. The racial equity task force of the American Federation of Teachers defines cultural competency as, 
The capacity to understand, respect and respond effectively to different students' cultures, communities and power dynamics across social groups: integrating personal awareness with a systematic change orientation. (The American Federation of Teachers Racial Equity Task Force, 2015, p.6)

Gay (1993) first described the issues that arise when educators and students have cultural differences by identifying the following areas that are impacted; cultural values, patterns of communication, cognitive processing, task performance, work habits, presentation styles and approaches to problem solving. Gay (1993) found that when students are negotiating between two or more cultural systems this can distract them from functioning well academically.

Some researchers recommended that educators examine their cultural beliefs to gain insight into their own cultural bias (Chen, Nimmo \& Fraser, 2009; Harmon, KasaHendrickson, \& Neal, 2010). Self-reflection is an important step in gaining knowledge about cultural diversity. When one examines their own personal beliefs, they will recognize their cultural frame of reference, beliefs about race and ethnicity and how this may create bias about people from cultures other than their own (Dray \& Wisneski, 2011; Rychly \& Graves, 2012). "Many teachers simply do not have frames of reference and points of view similar to their ethnically and culturally different students because they live in different existential worlds" (Gay, 1993, p. 287).

Chen et al. (2009) developed a self-study tool for educators to prepare them to work with culturally and linguistically diverse (CLD) students (see Appendix D). This tool is appropriate for special education educators as they increasing find more ELL students referred to special education. When designing the tool, the researchers sought feedback from numerous sources including experts in the diversity field, pre service 
teachers and practicing educators. The purpose of the tool is to provide a structure for self-reflection and assist educators in examining their practice. The tool is organized into a series of questions divided into four areas: raising self-awareness, physical classroom environment, pedagogical environment and relationships with students' families and community. The results of the self-reflection tool illuminate areas in which educators may wish to examine their own practice and target areas in which to improve.

Culturally responsive teaching (CRT) strategies to engage CLD students, including students currently or previously enrolled in an ELL program who are receiving special education services, include emphasizing verbal interactions, facilitating divergent thinking, focusing on real world tasks, encouraging informal peer guided discussion groups and guiding journal writing (Salend \& Duhaney, 2005). Culturally responsive practices also include displaying student work on posters representing diverse groups throughout the classroom, using small cooperative learning groups and peer tutoring within the classroom (Harmon et al., 2010). When implementing culturally responsive practices for CLD students with disabilities, Utley, Obiakor, and Bakken (2011) stressed the need for special educators to incorporate the students' cultural beliefs and prior learning.

Herrera, Holmes, and Kavimandan (2012) maintained that there are various untapped cultural and linguistic funds of knowledge bases that encompass the background knowledge a CLD student brings to school. They suggested creating a lowrisk learning environment in which CLD students can incorporate these knowledge bases. They defined three types of knowledge they consider as part of a CLD student's 
knowledge base; funds of knowledge from home, prior knowledge learned in their community and academic knowledge learned at school. Moll, Amanti, Neff, and Gonzalez (1992) defined "funds of knowledge" as "historically accumulated knowledge and skills" (p.133) within households of CLD families. In their research, they paired a researcher with an educator and visited CLD students' homes to interview the parents using a questionnaire. From the information they collected from both interviews and observations, they found funds of knowledge, which they defined as household and community resources. To encourage more engagement and address the needs of their CLD students, they incorporated these funds of knowledge into lessons on topics of interest that were relevant to the student and involved parents in the classroom as resources.

Disability is perceived differently across various cultures and educators' practice can be enhanced by having knowledge about the expectations, learning styles and beliefs about disability from the perspective of their students' culture (Harmon et al., 2010). Students currently or previously enrolled in an ELL program who are receiving special education services can benefit from the incorporation of culturally responsive practices. In the next sections, I discuss the importance of understanding the impact of the acculturation process and how the use of research based pre-referral strategies can prevent school teams from making a disproportionate number of referrals of ELL students for special education evaluation. 


\section{Acculturation}

The separation of people from their native land and culture brings not only physical dislocation but also social adjustment and linguistic challenges. (Stromquist, 2012, p. 200)

Understanding the acculturation process is essential when developing the skills to practice culturally responsive teaching when working with students currently or previously enrolled in an ELL program who are receiving special education services. The acculturation process can have a profound impact on a student's ability to learn and has been given little attention in the discussion about culturally responsive teaching and disproportionate referral of ELL students for special education evaluation. I propose that knowledge of the acculturation process is critically important when addressing concerns about an ELL student's academic progress as the student has a plethora of information to decipher about the dominant culture. The Migration Policy Institute reports that in 2013, 61.6 million individuals both U.S. and foreign born spoke a language other than English at home and 41\% (25.1 million) were considered limited English proficient which would qualify them for ELL instruction in school (Migration Policy Institute, 2015). The challenges these students face upon entering the K-12 school system are complex. In addition to comprehending academic instruction delivered in English, ELL students cope with developing an understanding of and navigating the nuances of codes of personal conduct of the dominant culture (Stromquist, 2012). 


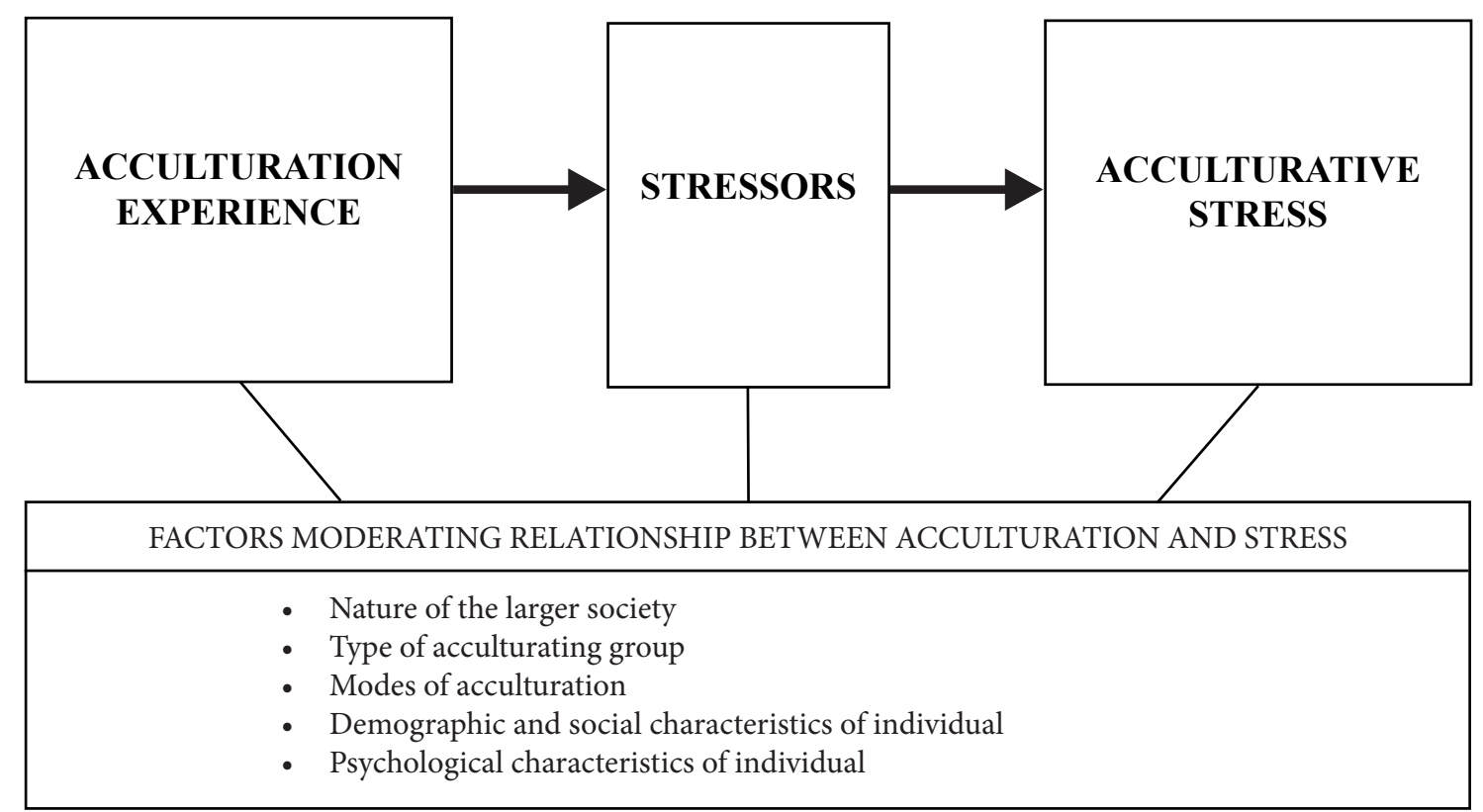

Figure 3. The acculturation process. Adapted by K. DuBois from "Comparative Studies of Acculturative Stress," by J. W. Berry, U. Kim, T. Minde, and D. Mok, 1982, International Migration Review, 21(3), p. 493.

Acculturation is the process of socially, psychologically and academically adapting to a host culture (DeHaan, 2011). It is a process of re-socializing by adapting to new values and practices of the host culture while retaining some aspects of your home culture (See Figure 3). The host culture is the dominant group who has the most power (Dow, 2011). Acculturation develops at a different pace and to varying degrees depending on one's contact with the host culture and experiences prior to arrival. The length of residence in the U.S. does not necessarily mean an immigrant has adapted to a host culture (DeHaan). There are numerous factors illustrated in Figure 4 that can impact the stress associated with the acculturation process (Berry et al., 1982).

Teske and Nelson (1974) described acculturation as a process and each individual, even within one family, will react differently and their process will vary over time. There are many factors that influence a student's acculturation process including amount of 
time spent interacting with people from the host culture, the circumstances from which the student came and parental stress. Direct contact with members of the host culture is necessary for acculturation to occur (Dow, 2011). When a student is determined eligible for ELL instruction, they leave their homeroom to spend a portion of their school day receiving English language development instruction with other non-native English speakers. The degree of acculturation a student experiences is influenced not only by the amount of time spent among the host culture, but of the acculturation of their cultural group (Teske \& Nelson, 1974). An ELL student's exposure to the host culture may be limited to a few hours a day and may not include personal interaction.

Teske and Nelson (1974) stated that assimilation occurs when an immigrant starts to identify with the dominant group by acquiring the language and social rituals of the dominant group. An ELL student's past functional, developmental and educational history, cultural and linguistic considerations, story of arrival to the U.S., whether voluntary of involuntary, residency status and years in the host country can impact language development (Rinaldi \& Samson, 2008). This leads one to ponder whether a request for evaluation for special education of ELL student is indeed a request for an assessment of assimilation.

The anxiety created by dealing with an unfamiliar host culture can cause tremendous stress, referred to as acculturation stress. This stress can impact how an ELL student performs in the host culture. Acculturative stress takes a toll on the psychological and physical health of immigrants undergoing acculturation (Berry et al., 1982). There are five areas of change affected during the acculturation process including physical, 
biological, cultural, social and psychological change. An immigrant may experience physical changes when moving to a different environment, for example, a new type of housing with increased density can be very stressful. Biological stress can be experienced when an immigrant is exposed to new diseases. Established social relationships and ways of relating can change when a parent now depends on their child, the ELL student, to navigate the host culture for them. All of these changes have a psychological impact and can lead to anxiety, confusion, depression and feelings of displacement, marginalization and alienation and impact a student's ability to learn in an unfamiliar language.

Voluntary immigrants are people who choose their location and planned to emigrate, they tend to experience what is called, "integrated acculturation", maintaining their own cultural identity by retaining values, beliefs and attitudes of their culture and also developing relationships in the host community (Dow, 2011). Involuntary immigrants are refugees who are displaced by violence or persecution, they had no choice as to where they emigrate and often languished in refugee camps for many years as did Daod, who was the inspiration for this study. His story was told in Chapter 1; he was born and raised in a refugee camp prior to his arrival in the U.S. and was diagnosed with posttraumatic stress disorder soon after his arrival. Yet within a year and half of his arrival he was referred to and placed in the most restrictive placement available in special education as a student with an intellectual disability. Children may attend school in a refugee camp, if offered, infrequently. Prior to their departure from the refugee camp, families are given very little notice as to when they will depart and where they will emigrate to. 
Refugees as involuntary immigrants experience acculturative stress more severely and frequently than voluntary newcomers (Phillimore, 2011). They report experiencing grief and feeling unsettled and displaced. After living for years with uncertainty in a refugee camp before resettlement, acculturation stress can be caused by too much change that occurs rapidly with little time to adjust. A study completed with Somalian refugees in Canada found that they experienced a high rate of acculturation stress due to loss of loved ones and social status, a lack of social support, challenges navigating an unfamiliar environment and difficulty learning a new language (Matheson, Jorden, \& Anisman, 2008). Many children who are involuntary immigrants and who are identified by the school system as ELL students are then placed with their same age peers in a classroom environment soon after their arrival, exposing them to academic instruction in an unfamiliar language. The differences in personal interaction, urban versus rural mores and expectations of the host culture can be unclear. Ellis et al. (2010) found that three fourths of the Somali adolescent ELL students they interviewed had experienced discrimination and reported high levels of post-traumatic disorder and depression. Cultural changes occur when one is adjusting to the host culture and dealing with unfamiliar political, economic, religious and social institutions (Berry et al., 1982). Interrupted schooling caused by war, violence and trauma has a significant impact on the school readiness of refugees, they may be several years behind in their schooling from their own country yet are placed at the grade level appropriate for their age when they arrive in the U.S. (McWilliams \& Bonet, 2016). This group of ELL students may experience cultural dissonance in school caused by a lack of understanding of the 
expectations of the western style of teaching which is individualistic rather than collectivistic, seeing individuals as members of group (DeCapua \& Marshall, 2015).

ELL students do not have the option of slowly exposing themselves to the host culture with cultural brokers by their sides (Dow, 2011). Their parents may also experience parental stress due to contrasting parenting traditions creating further strain on the ELL student (DeHaan, 2011). All of these factors impact how an ELL student will perform academically and need to be thoroughly considered prior to a referral for special education evaluation.

\section{Pre-Referral Strategies}

There are research based pre-referral intervention strategies that can be implemented to address concerns about the academic progress of students currently or previously enrolled in an ELL program prior to initiating a request for a special education evaluation. Providing strategies to address an ELL student's specific academic concerns when issues arise can prevent unnecessary referral and placement in special education thereby reducing the disproportionate numbers of referrals to special education for these students (Fiedler et al., 2006). A school team meeting including family members can convene to generate strategies using the strengths of the team members for collaborative problem solving. The strategies generated can be refined prior to a referral being initiated. Klingner and Harry (2006) observed school teams and found that they were not functioning as a solution based entity but rather "students were pushed towards testing" (p. 2274). The participants in my study reported that ELL students were referred for special education evaluation without employing pre-referral strategies in a general 
education setting. An ELL student would arrive in their special education classroom with no paperwork documenting the discussion or use of pre-referral strategies, this led my participants to question the validity of the special education eligibility. In the following section, research-based pre-referral processes and strategies are introduced, the use of these methods can assist school teams in providing solutions to the academic challenges their ELL students may face and prevent the disproportionate referral of ELL students for special education evaluation.

Burr et al. (2015) completed a report for The National Center for Education Evaluation and Regional Assistance after an extensively reviewing academic articles and state policies about students with dual eligibilities for ELL and special education services in the 20 states with the highest number of ELL students including Oregon. They concluded by recommending the following five guiding principles that they propose districts adopt as practice.

A clear district policy stating that additional considerations will be used when evaluating ELL students for special education

Test accommodations provided for ELL students on all assessments

Use of additional criteria accompanied by the English Language Proficiency Assessment (ELPA) when determining when an ELL student in special education is exited from the English language support programs

Production and distribution of manuals to ELL and special educators detailing how to identify and support ELL students with special education services and professional development specific to the manual

Completion of all steps in the Response to Intervention (RTI) strategy prior to a referral for special education services for an ELL student

Fifty education websites were reviewed by Scott et al. (2014) from states across the country to see how the needs of CLD students including students currently or 
previously enrolled in an ELL program, are addressed when considering a special education evaluation. They wanted to find out what guidance was recommended to practitioners in the field. They found that thirty-six states did not specifically address CLD and ELL students in regards to special education. Ten states including Oregon provided guidance to school districts within their state on the use of pre-referral strategies for ELL students prior to a referral for a special education evaluation. They discovered that there is no national consensus regarding pre-referral processes or strategies for CLD and ELL students who are struggling academically prior to referral for the special education evaluation (Scott et al., 2014). The researchers singled out and recommended the information found on the Oregon's department of education website regarding these students yet none of the participants in my study had any knowledge of the guidelines produced by Oregon department of education as they had never received any professional development on this topic.

As a result of the review conducted by Scott et al. (2014), they offered numerous recommendations including the use of assessments in a student's native language, collecting family educational history and cultural practices that may impact education. As well as comparing student assessment data to true peers, other CLD and ELL students who are performing at the same level of language proficiency, rather than against native English speakers. In addition they suggested becoming knowledgeable about the acculturation process, requiring cultural brokers, language interpreters and ELL teachers to be members of evaluation team, providing on going professional development to teachers on the delivery of culturally sensitive instruction and using the three tiered 
responsive to intervention (RTI) model. In 2011, the New York department of education issued a memorandum that was distributed to multidisciplinary teams in all school districts throughout the state. They required all teams deliberating about an ELL students' eligibility for special education to include staff who are knowledgeable about both ELL and disability issues (Reyes-Carrasquillo, Rodriguez, \& Kaplan, 2014).

Hoover and Erickson (2015; see Appendix E) designed a four-step flowchart accompanied by a rating guide, including cultural and linguistic factors. This tool was designed for use by school teams when considering a referral for special education evaluation for CLD students, including students currently or previously enrolled in an ELL program, to special education. Based on an extensive literature review, feedback from expert, practitioner and focus group participants, Hoover and Erickson piloted the guide as a pre-referral tool in one rural school district. The district's referral data indicated a history of a disproportionate number of referrals of CLD students including ELL students for special education evaluation. When designing the tool, they were cognizant to create a guide that was user friendly and efficient for use by numerous school personnel. The researchers identified four areas that were critically important for teams to examine when considering a referral for an ELL student. These are: (a) examining the quality of instruction, (b) considering language development and usage, (c) using unbiased classroom assessment and progress monitoring and (d) reflecting on the home and school relationship. After using the tool, the information gathered was then examined by the cultural and linguistic diversity referral team, the school district found 
that three out of seven referrals did not conclude in an evaluation for special education (Hoover \& Erickson).

Keller-Allen (2006) reviewed the referral policies of seven states, in regards to the referral of ELL students for special education evaluation, and concluded with a recommendation that the assessment of an ELL student's language proficiency must be measured against their true peers, other CLD and ELL students who are performing at the same level of language proficiency, rather than against native English speakers. Only then can issues related to language acquisition be eliminated from consideration when conducting an evaluation for special education eligibility. If an ELL student is found eligible for special education services, it is important that they continue instruction provided by the ELL department in English language development (Reyes-Carrasquillo et al. 2014; Scott et al., 2014).

In this study, participants reported that for most of their ELL students, when they were found eligible for special education services, they were dropped from the ELL program. Participants felt particularly unprepared for teaching English language acquisition, as it is not included in pre service training for special education teachers.

\section{Response to Intervention}

Prior to referring an ELL student for special education, the IDEA of 2004 recommends using response to intervention (RTI) as a strategy and monitoring method to address areas of academic need in addition to or in place of standardized IQ tests when considering special education placement (Klingner \& Harry, 2006). The participants in this study were not familiar with this strategy, RTI was not used for the ELL students 
found eligible for special education and then placed in their special education classrooms. In the following section, RTI is described as well as the modifications some researchers have made to the method to accommodate the unique needs of ELL students.

RTI “integrates assessment and intervention within a multi-tiered prevention system to maximize student achievement and to reduce behavioral problems" (Artiles \& Kozleski, 2006, p. 950). RTI is a multi-tiered system, each tier provides interventions of increasing intensity (Urso, 2013). In tier one, a school team meeting is convened to include family members and specific areas of concern are identified, research based interventions are discussed and designated to be put into place in the general education setting, student progress is then monitored. If the student does not make adequate progress in the time frame determined by the school team, they are moved to the second tier of intervention where more intensive interventions are provided and progress monitoring continues within the general education classroom. If the student does not respond to the interventions they are moved to tier three, which is a referral for evaluation to special education.

\section{Response to Intervention and Cultural Responsiveness}

It is important to consider cultural factors when implementing RTI to insure interventions are culturally appropriate and address the unique needs of ELL students so that the intervention strategy does not inadvertently contribute to referral for special education evaluation (Esparza Brown \& Doolittle, 2008; Linan-Thompson, Cirino, \& Vaughn, 2007; Orosco \& Klingner, 2010). School teams using the protocol for RTI should include school personnel who are knowledgeable about language acquisition and 
cognitive development (Klingner \& Harry, 2006). Discussions about the second-language acquisition process and how to distinguish between language acquisition and acculturation issues, trauma and true learning disability are critical to consider in each tier of intervention (Artiles \& Kozleski, 2006).

Researchers focusing on ELL students have proposed adaptations of the RTI model to address the cultural and linguistic issues unique to these students, in the next section one of those models designed by two of the preeminent researchers in the field is described. Esparza Brown and Doolittle (2008) proposed a cultural, linguistic and ecological framework for use with RTI as a strategy to parse cultural and language issues from disability when using RTI with ELL students (see Figure 5). They explained that each school district should have specialists highly trained to differentiate between cultural and linguistic differences from learning disabilities who are required to participate with a school team when there is deliberation about the academic needs of ELL students. They presented a three-tiered RTI model incorporating these principles. The advantage of their model is that it allows comparison of ELL students to their peers from similar cultural and linguistic backgrounds, their true peers, rather than using national norms based on white middle class students. Their RTI model requires the collaboration of numerous school staff including speech language pathologist, special education teacher, general education teacher, ELL teacher, school psychologist and specialist trained to differentiate language between language and cultural issues and learning disability. Special educators are not typically part of the school team using the traditional RTI method, the model proposed by Esparza Brown and Doolittle (2008) has 
recommended that the expertise special educators have in learning disability is highly valuable to a pre-referral team. A discussion among this expanded school team can produce strategies meaningful and appropriate specifically for ELL students. The inclusion of both a specialist in language acquisition versus learning disability and a special educator in the RTI process can reduce the disproportionate number of ELL students referred for special education evaluation (Esparza Brown \& Doolittle, 2008).

\section{TIER 1}

Students receive appropriate instruction, behavioral support and regular progress monitoring. Students are provided additional instruction and/or support in a general education setting.

\section{TIER 2}

Students who do not make progress in TIER 1 receive more intensive support by providing them with more intensive interventions in the general education setting.

Figure 4. Response to intervention tiers. Adapted from "A Cultural, Linguistic, and Ecological Framework for Response to Intervention With English Language Learners," by J. Esparza Brown and J. Doolittle, 2008, TEACHING Exceptional Children, 40(5), p. 67.

\section{Culturally Responsive Positive Behavior Interventions and Support}

The final pre-referral strategy to be introduced is culturally responsive positive behavior interventions and supports (CRPBIS). 
CRPBIS proposes a paradigm shift in the PBIS service delivery model from a normative and deterministic concept of culture to an instrumental conceptualization, which includes moving away from surface outcome disparities to actual social and institutional processes of injustice that maintain and reproduce the outcome disparities in U.S. schools. (Bal, 2015. p. 11)

Positive behavior interventions and supports (PBIS) is a three tiered prevention model of behavioral support implemented in some school districts to address the historically disproportionate referral of CLD students, including students currently or previously enrolled in an ELL program, for evaluation for special education under the eligibility category of emotional disturbance because of perceived behavioral disorders (Bal). The original PBIS model does not consider cultural and linguistic factors that affect behavior and therefore is a not culturally responsive method (Bal). To further decrease the racial disproportionality represented in behavioral referrals for these students, Bal proposed culturally responsive positive behavioral interventions and supports (CRPBIS) as a new model using the PBIS model as a base. The CRPBIS model incorporates cultural responsiveness by recognizing that behavior takes place within the context of diverse cultural and linguistic practices and that cultural patterns influence learning and communication styles as well as the perceptions of roles of authority and behavior. Culture is dynamic, multifaceted, filled with conflicts and changing negotiations, resistance, compliance and differences between power and privilege (Bal). "CRPBIS proposes a paradigm shift in the PBIS service delivery model from a normative and deterministic concept of culture"(Bal, p.11).

Numerous researchers have investigated and made recommendations to address the disproportionate number of ELL students referred to special education. There are sound 
pre-referral strategies that are research based available to school districts though the participants in my study had no exposure to these valuable tools.

\section{Conclusion}

Throughout the history of special education, there has been documentation and discussion regarding the disproportionate number of CLD students including ELL students placed in special education and this has been linked to issues of equity and social justice, "Over representation is a multidimensional predicament with deep historical and systematic roots." (Artiles, 2003, p. 175). The purpose of this study was to describe special educators' experiences teaching students currently or previously enrolled in the English language learner program who are receiving special education services, by exploring their views of what supports, resources and strategies contribute to student success and teachers' views of the eligibility determination and referral process. The fact that no resources in the form of professional development, resources and instructional strategies were provided to the participants was an indication that these students and their teachers are marginalized. They were also not included in the referral and placement process for ELL students though they possess expertise in disability issues. Though my sample was smaller than anticipated, the results were strikingly consistent. Through my interviews with the participants I found that their persistent attempts to seek collaboration and resources from both the special education and ELL departments were ignored and illustrates how the participants and their students are not valued by administrators who have the authority to provide the necessary resources. What I discovered was that a segregated system still exists in which these students' academic needs were not only 
dismissed but consistently ignored over time. Artiles (2003) explained that special education is a historically segregated system that has been used over decades to marginalize students deemed problematic.

Mueller, Singer and Carranza (2006) conducted a national survey of 375 special educators serving ELL students with disabilities to assess the teachers' instructional practices. The majority of the respondents reported they were underprepared to work with ELL students because of a lack of resources and support and lack of knowledge of language development and the cultural differences that intersect with family involvement in the process. My results are in alignment with their findings.

Qualitative interview studies, such as the one I conducted, reveal what seems to be most salient or important phenomena and can provide the needed direction for subsequent quantitative research such as developing questions for survey research with a larger sample (Maxwell, 2005). Now that I found deficiencies in the areas of supports, resources, instructional strategies and pre referral practices for educators working with students currently or previously enrolled in the English language learner program who are receiving special education services for students, my interest to explore this topic has grown. I would like to rewrite my interview questions as survey questions and send a survey to special educators in the states in the U.S. with the highest number of ELL students.

I found that the acculturation process was not discussed in the research focusing on ELL students and special education. Knowledge of the acculturation process is essential when deliberating over the academic needs of ELL students who may be 
struggling. I would like to pursue this topic and include questions about special educators' knowledge of this process in my survey.

According to the American Community Survey Report published by the United States Census Bureau in 2011, out of population of 291.5 million people aged 5 and over, 60.6 million people (21\%) spoke a language other than English at home. They further reported that in 1980, 23.1 million people spoke a language other than English compared to 59.5 million people in 2010 , this represents a $158 \%$ increase and illustrates how the United States continues to become more diverse (Ryan, 2013). It is of utmost importance that we as educators are prepared to adequately determine when special education would be appropriate and beneficial for ELL students and have the knowledge and skills necessary to address their unique academic needs when these students do require special education. 


\section{REFERENCES}

Abedi, J. (2006). Psychometric issues in ELL assessment and special education eligibility. Teachers College Record, 108(11), 2282-2303.

Ahram, R., Fergus, E., \& Noguera, P. (2011). Addressing racial/ethnic disproportionality in special education: Case studies of suburban school districts. Teachers College Record, 113(10), 2233-2266.

Almanza de Schonewise, E. K., \& Klingner, J. K. (2012). Linguistic and cultural issues in developing disciplinary literacy for adolescent English language learners. Topics in Language Disorders, 32(1), 51-68.

Anyon, Y. (2009). Sociological theories of learning disabilities: Understanding racial disproportionately in special education. Journal of Special Education, 32(1), 4457.

Artiles, A. J. (1998). The dilemma of difference: Enriching the disproportionality discourse with theory and context. The Journal of Special Education, 32(1), 3236.

Artiles, A. J. (2003). Special education's changing identity: Paradoxes and dilemmas in views of culture and space. Harvard Educational Review, 73(2), 164-202.

Artiles, A. A., \& Bal, A. (2008). The next generation of disproportionality research: Toward a comparative model in the study of equity in ability differences. The Journal of Special Education, 42(1), 4-14. doi:10.1177/0022466907313603

Artiles, A. A., \& Klingner, J. K. (2006). Forging a knowledge base on English language learners with special needs: Theoretical, population, and technical issues. Teachers College Record, 108(11), 2187-2194.

Artiles, A. A., \& Kozleski, J. K. (2006). What counts as response to intervention in RTI? A sociological analysis. Psicothema, 22(4), 949-954.

Artiles, A. J., Kozleski, E. B., Trent, S. C., Oscher, D., \& Ortiz, A. (2010). Justifying and explaining disproportionality, 1968-2008: A critique of underlying views of culture. Exceptional Children, 76(3), 279-299.

Artiles, A. A., Rueda, R., Salazar, J. J., \& Higareda, I. (2005). Within-group diversity in minority disproportionate representation: English language learners in urban school districts. Exceptional Children, 71(3), 283-300.

Artiles, A. J., \& Trent, S. C. (1994). Overrepresentation of minority students in special education: A continuing debate. The Journal of Special Education, 27(4), 410-437. 
Bal, A. (2015). Culturally responsive behavioral interventions and supports (WCER Working Paper No. 2015-9). Retrieved from http://www.wcer.wisc.edu/ publications/workingPapers/papers.php

Beratan, G. D. (2008). The song remains the same: Transposition and the disproportionate representation of minority students in special education. Race Ethnicity and Education, 11(4), 337-354. doi:10.1080/13613320802478820

Berry, J. W., Kim, U., Minde, T., \& Mok, D. (1982). Comparative studies of acculturation stress. International Migration Review, 21(3), 491-511.

Billingsley, B. (2004). Special education teacher retention and attrition: A Critical analysis of the research literature. The Journal of Special Education, 38, 39-55.

Blanchett, W. J. (2006). Disproportionate representation of African American students in special education: Acknowledging the role of white privilege and racism. Educational Researcher, 35(6), 24-28.

Blanchett, W. J., Klingner, J. K., \& Harry, B. (2009). The intersection of race, culture, language, and disability: Implications for urban education. Urban Education, 44(4), 389-409. doi:10.1177/0042085909338686

Bollmer, J., Bethel, J., Garrison-Mogren, R., \& Brauen, M. (2007). Using the risk ratio to assess racial/ethnic disproportionality in special education at the school-district level. The Journal of Special Education, 41(3), 186-198.

Bonilla-Silva, E. (1996). Rethinking racism: Toward a structural interpretation. American Sociological Review, 62, 465-480.

Brantlinger, E., Jimenez, R., Klingner, J., Pugach, M., \& Richardson, V. (2005).

Qualitative studies in special education. Exceptional Children, 71(2), 195-207.

Brown, M. R. (2007). Educating all students: Creating culturally responsive teachers, classrooms and, schools. Interventions in School and Clinic, 43(1), 57-62.

Burr, E., Haas, E., \& Ferriere, K. (2015). Identifying and supporting English learner students with learning disabilities: Key issues in the literature and state practice (REL 2015-086). Washington, DC: U.S. Department of Education, Institute of Education Sciences, National Center for Education Evaluation and Regional Assistance, Regional Educational Laboratory West. Retrieved from http://ies.ed.gov/ncee/edlabs

Charmaz, K. (2006). Constructing grounded theory. Thousand Oaks, CA: Sage. 
Chen, D. W., Nimmo, J., \& Fraser, H. (2009). Becoming culturally responsive early childhood educator: A tool to support reflection by teachers embarking on the anti-bias journey. Multicultural Perspectives, 11(2), 101-106.

Chu, S. (2011). Teacher perceptions of their efficacy for special education referral of students from culturally diverse backgrounds. Education, 132(1), 3-14.

Cook-Morales, V. J., Robinson-Zanartu, C. A., \& Green, T. D. (2006). When part of the problem becomes part of the solution: Moving from evaluation to assessment. The Special Edge, 20(1), 6-16.

Coutinho, M. J., \& Oswald, D. P. (2000). Disproportionate representation in special education: A synthesis and recommendations. Journal of Child and Family Studies, 9(2), 135-156.

Coutinho, M. J., Oswald, D. P., \& Best, A. M. (2002). The influence of sociodemographics and gender on the disproportionate identification of minority students as having learning disabilities. Remedial and Special Education, 23(1), 49-59.

Creswell, J. W. (1994). Research design: Qualitative and quantitative approaches. Thousand Oaks, CA: Sage.

Creswell, J. W. (2005). Educational research: Planning, conducting, and evaluating quantitative and qualitative research. Upper Saddle River, NJ: Pearson Education.

Creswell, J. W. (2007). Qualitative inquiry and research design: Choosing among five approaches (2nd ed.). Thousand Oaks, CA: Sage.

DeCapua, A. \& Marshall, H. W. (2015). Reframing the conversation about students with limited or interrupted formal education: From achievement gap to cultural dissonance. NASSP Bulletin, 99(4), 356-370.

DeHaan, M. (2011). The reconstruction of parenting after migration: A perspective from cultural translation. Human Development, 54, 376-399.

Desimone, L. M. (2009). Improving impact studies of teachers' professional development toward better conceptualization and measures. Educational Researcher, 38(3), 181-199.

Dingle, M. P., Brownell, M. T., Leko, M. M., Boardman, A. G., \& Haager, D. (2011). Developing effective special education reading teachers: The influence of professional development, context, and individual qualities. Learning Disability Quarterly, 34(1), 87-103. 
Dow, H. D. (2011). The acculturation processes: The strategies and factors affecting the degree of acculturation. Home Health Care Management and Practice, 23, 221227. doi: $10.1177 / 1084822310390877$

Dray, B. J., \& Wisneski, D. B. (2011). Mindful reflection as a process for developing culturally responsive practices. TEACHING Exceptional Children, 44(1), 28-36.

Dunn, L. M. (1968). Special education for the mildly retarded: Is much of it justifiable? Exceptional Children, 23, 5-21.

Ellis, H. B., Lincoln, A., MacDonald, H. Z., Lunk-Gillis, J., Strunin, L., \& Cabral, J. (2010). Discrimination and mental health among Somali refugee adolescents: The role of acculturation and gender. American Journal of Orthopsychiatry, 80(4), 564-575.

Esparza Brown, J. D., \& Doolittle, J. (2008). A cultural, linguistic and ecological framework for response to intervention with English language learners. TEACHING Exceptional Children, 40(5), 66-72.

Fiedler, C. R., Chiang, B., Van Haren, B., Jorgenson, J., Hlaberg, S., \& Boreson, L. (2006). Culturally responsive practices in schools: A checklist to address disproportionality in special education. TEACHING Exceptional Children, 40(5), $52-59$.

Garcia, E. E., \& Cuellar, D. (2006). Who are these linguistically culturally diverse students? Teachers College Record (108)11, 2220-2246

Garcia, S. B., \& Tyler, B. (2010). Meeting the needs of English language learners with learning disabilities in the general curriculum. Theory Into Practice, 49, 113-120. doi:10.1080/00405841003626585

Gaviria-Soto, J. L., \& Castro-Morera, M. (2005). Beyond over-representation: The problem of bias in the inclusion of minority group students in special education programs. Quality and Quantity, 39, 537-558. doi:10.1007/s11135-005-1606-3

Gay, G. (1993). Building cultural bridges. Education and Urban Society, 25(3), 285-299.

Gay, G. (2002). Culturally responsive teaching in special education for ethnically diverse students: Setting the stage. Qualitative Studies in Education, 15(6), 613-629.

Gay, L. R., \& Airasian, P. (2000). Educational research: Competencies for analysis and application. Upper Saddle River, NJ: Pearson Education.

Harmon, C., Kasa-Hendrickson, O., \& Neal, L. I. (2010). Promoting cultural competencies for teachers of students with significant disabilities. Research and Practice for Persons with Severe Disabilities, 34(3-4), 137-144. 
Hart, J. E. (2009). Strategies for culturally and linguistically diverse students with special needs. Preventing School Failure, 53(3), 197-206.

Hatch, J. A. (2002). Doing qualitative research in education settings. Albany, NY: State University of New York Press.

Herrera, S. G., Holmes, M. A., \& Kavimandan, S. K. (2012). Bringing theory to life: Strategies that make culturally responsive pedagogy a reality in diverse secondary classrooms. International Journal of Multicultural Education, 14(3), 1-19.

Hoover, J. J., \& Erickson, J. (2015). Culturally responsive special education referrals of English language learners in one rural county school district: Pilot project. Rural Special Education Quarterly, 34(4), 18-28.

Hoover, J. J., \& Patton, J. R. (2005). Differentiating curriculum and instruction for English language learners with special needs. Intervention in School and Clinic, 40(4), 231-235.

Individuals with Disabilities Education Act of 2004 (2004).

Keller-Allen, C. (2006). English language learners with disabilities: Identification and other state policies and issues. Alexandria, VA: National Association of State Directors of Special Education.

Klingner, J. K., \& Artiles, A. J. (2006). English language learners struggling to learn to read: Emergent scholarship on linguistic differences and learning disabilities. Journal of Learning Disabilities, 39(5), 386-389.

Klingner, J. K., Artiles, A. J., Kozleski, E. B., Harry, B., Zion, S., Tate, W., . . Riley, D. (2005). Addressing the disproportionate representation of culturally and linguistically diverse students in special education through culturally responsive educational systems. Educational Policy Analysis Archives, 13(38), 1-43.

Klingner, J. K., \& Harry, B. (2006). The special education referral and decision-making process for English language learners: Child study team meetings and placement conferences. Teachers College Record, 108(11), 2247-2281.

Klingner, J. K., \& Soltero-Gonzalez, L. (2009). Culturally and linguistically responsive literacy instruction for English language learners with learning disabilities. Multiple Voices for Ethnically Diverse Exceptional Learners, 12(1), 4-20.

Kolano, L. Q., Davila, L. T., LaChance, J., \& Coffey, H. (2013). Multicultural teacher education: Why teachers say it matters in preparing them for English language learners. The Catesol Journal, 25(1), 41-64. 
Kose, B. W., \& Lim, E. Y. (2010). Transformative professional development: Relationship to teachers' beliefs, expertise and teaching. International Journal of Leadership in Education, 13(4), 393-419.

Kozleski, E. B., \& Smith, A. (2009). The complexities of systems change in creating equity for students with disabilities in urban schools. Urban Education, 44(4), 427-451.

Lakin, J. M., \& Lai, E. R. (2012). Multigroup generalizability analysis of verbal, quantitative, and nonverbal ability tests for culturally and linguistically diverse students. Educational and Psychological Measurement, 72(1), 139-158. doi: $10.1177 / 001316441408074$

Lesaux, N. K. (2006). Building consensus: Future directions for research on English language learners at risk for learning disabilities. Teachers College Record, 108(11), 2406-2438.

Linan-Thompson, S. (2010). Response to intervention: English language learners and disproportionate representation: The role assessment. Psicothema, 22(4), 970974.

Linan-Thompson, S., Cirino, P. T., \& Vaughn, S. (2007). Determining English language learner's response to interventions: Questions and some answers. Learning Disability Quarterly, 30, 185-195.

Linn, D., \& Hemmer, L. (2011). English language learner disproportionality in special education: Implications for the scholar-practitioner. Journal of Educational Research and Practice, 1(1), 70-80. doi:10.5590/JERAP.2011.01.1.06

MacMillan, D. L., \& Reschly, D. J. (1998). Overrepresentation of minority students: The case for greater specificity or reconsideration of variables examined. The Journal of Special Education, 32(1), 15-24.

Macswan, J., \& Rolstad, K. (2006). How language proficiency tests mislead us about ability: Implications for English language learner placement in special education. Teachers College Record, 108(11), 2304-2328.

Mandell, D. S., Ittenbach, R. F., Levy, S. E., \& Pinto-Martin, J. A. (2007). Disparities in diagnoses received prior to a diagnosis of autism spectrum disorder. Journal of Autism and Developmental Disorders, 37, 1795-1802.

Matheson, K., Jorden, S., \& Anisman, H, (2008). Relationship between trauma experiences and psychological, physical and neuroendocrine functioning among Somalian refugees: Medicating a role of coping with acculturation stressors, Journal of Immigrant Minority Health, 10, 291-304. 
Maxwell, J. A. (2005). Qualitative research design: An interactive approach $\left(2^{\text {nd }}\right.$ ed.; Vol. 41, Applied social sciences research methods series). Thousand Oaks, CA: Sage.

Maxwell, L. A., \& Shah, N. (2012). Evaluating ELLs for special needs a challenge. Education Week, 32(2), 1-2.

McCardle, P., Mele-McCarthy, J., Cutting, L., Leos, K., \& D'Emilio, T. (2005). Learning disabilities in English language learners: Identifying the issues. Learning Disabilities Research and Practice, (20)1, 1-5. doi:10.1111/j.15405826.2005.00114.x

McWilliams, J. A. \& Bonet, S. W. (2016). Continuums of precarity: Refugee youth transitions in American high schools. International Journal of Lifelong Education, 35(2), 153-170.

Merriam, S. B. (2009). Qualitative research: A guide to design and implementation (2nd ed.). San Francisco, CA: Jossey-Bass.

Migration Policy Institute. (2015). Frequently Requested Statistics on Immigrants and Immigration in the United States (ELL Information Center Fact Sheet Series). Retrieved from http://www.migrationpolicy.org/article/frequently-requestedstatistics-immigrants-and-immigration-united-states

Moll, L. C., Amanti, C., Neff, D., \& Gonzalez, N. (1992). Funds of knowledge for teaching: Using a qualitative approach to connect homes and classrooms. Theory into Practice, 31(2), p. 132-141.

Mueller, T. G., Singer, G. H. S., \& Carranza, F. D. (2006). A national survey of the educational planning and instruction practices for students with moderate to severe disabilities who are English language learners. Research and Practice for Persons With Severe Disabilities, 31(3), 242-254.

No Child Left Behind Act of 2001 (2002).

Oregon Department of Education. (2015). Statewide Report Card, 2014-2015.

(November 30, 2015. Oregon Department of Education: Annual Report to the Legislature on Oregon Public Schools. Retrieved from http://www.ode.state.or.us/search/page/?id=1779

Oregon Department of Education. (2016). A summary to the legislature of the annual report to the legislature on English Language Learners, 2014-2015. Salem, Oregon: Author. 
Orosco, M. J., \& Klingner, J. (2010). One schools' implementation of RTI with English language learners: Referring to RTI. Journal of Learning Disabilities, 43(3), 269288.

Ortiz, A. A., Robertson, P. M., Wilkinson, C. Y., Liu, Y., McGhee, B. D., \& Kushner, M. I. (2011). The role of bilingual education teachers in preventing inappropriate referrals of ELLs to special education: Implications for response to intervention. Bilingual Research Journal, 34, 316-333. doi:10.1080/15235882.2011.628608

Oswald, D. P., \& Coutinho, M. J. (2006). Why it matters: What is disproportionate representation? The Special Edge, 20(1), 1-6.

Overton, T., Fielding, C., \& Simonsson, M. (2004). Decision making in determining eligibility of culturally and linguistically diverse learners: Reasons given by assessment personnel. Journal of Learning Disabilities, 37(4), 319-330.

Paneque, O. M., \& Barbetta, P. M. (2006). A study of teacher efficacy of special education teachers of English language learners with disabilities. Bilingual Research Journal, 30(1), 171-193.

Phillimore, J. (2011). Refugees, acculturation strategies, stress and integration. Journal of Social Policy, 40(3), 575-593.

Random House Webster's unabridged dictionary (2001). Random House Webster's unabridged dictionary ( $2^{\text {nd }}$ ed.) Random House Reference: New York. p. 1175.

Reyes-Carrasquillo, A., Rodriguez, D., \& Kaplan, L. (2014). New York state policies, mandates and initiatives on the education of English language learners. Journal of Multilingual Education Research, 5(5), 67-91. Retrieved from http://fordham.bepress.com/jmer/vol5/iss $1 / 5$

Rinaldi, C., \& Samson, J. F. (2008). English language learners and response to intervention: Referral considerations. TEACHING Exceptional Children, 40(5), 614.

Rueda, R., \& Windmueller, M. P. (2006). English language learners, LD, and overrepresentation: A multiple-level analysis. Journal of Learning Disabilities, 39(2), 99-107.

Ryan, C. (2013). Language use in the United States: 2011 (Report No. ACS-22). Retrieved from http://www.census.gov/library/publications/2013/acs/acs-22.html

Rychly, L., \& Graves, E. (2012). Teacher characteristics of culturally responsive pedagogy. Multicultural Perspectives, 14(1), 44-49. 
Saldana, J. (2013). The coding manual for qualitative researchers. London, England: Sage.

Salend, S. J., \& Duhaney, L. M. G. (2005). Understanding and addressing the disproportionate representation of students of color in special education. Intervention in School and Clinic, 40(4), 213-221.

Samson, J. F., \& Lesaux, N. K. (2009). Language-minority learners in special education: Rates and predictors of identification for services. Journal of Learning Disabilities, 42(2), 148-162. doi:10.1177/0022219408326221

Scott, A. N., Boynton Hauerwas, L. B., \& Brown, R. D. (2014). State policy and guidance for identifying learning disabilities in culturally and linguistically diverse students. Learning Disability Quarterly, 37(3), 172-185.

Skiba, R. J., Simmons, A. B., Ritter, S., Kohler, K., Henderson, M., \& Wu, T. (2006). The context of minority disproportionality: Practitioner perspectives on special education. Teachers College Record, 108(7), 1424-1459.

Strand, S., \& Lindsay, G. (2009). Evidence of ethnic disproportionality in special education in an English population. The Journal of Special Education, 43(3), 174-190.

Stromquist, N. P. (2012). The educational experiences of Hispanic immigrants in the United States: Integration through marginalization. Race Ethnicity and Education, 15(2), 195-221.

Sullivan, A. L. (2011). Disproportionality in special education identification and placement of English language learners. Exceptional Children, 77(3), 317-334.

Sullivan, A. L., \& Artiles, A. J. (2011). Theorizing racial inequity in special education: Applying structural inequity theory to disproportionality. Urban Education, 46(6), 1526-1552. doi:10.1177/0042085911416014

Talasow, O. personal communication, October 28, 2012.

Tedesco, B., \& Franks, E. (2012, October 20). ELLs and SPED: A response to intervention. Paper presented at the English language learners and special education: NJTESOL-NJBE Fall Conference, Galloway, NJ.

Teske, R. H. C. \& Nelson, B. H. (1974). Acculturation and assimilation: A clarification. American Ethnologist, 1(2), 351-367.

The American Federation of Teachers Racial Equity Task Force, AFL-CIO (AFT, 2015). Reclaiming the Promise of Racial Equity in Education, Economics and Our Criminal Justice System. P. 6. Washington, D.C. 
Urso, A. (2013). Introduction to response to intervention. Reading and Writing Quarterly, 29(1), 1-3.

U.S. Department of Education, Institute of Education Sciences, National Center for Education Statistics. (2013a). Digest of educational statistics, 2013 tables and figures. Table 204.20: Number and percentage of public school students participating in programs for English language learners, by state: Selected years, 2002-03 through 2011-12. Retrieved from www.nces.ed.gov/programs/digest/ d13/tables/dt13_204.20.asp

U.S. Department of Education, Institute of Education Sciences, National Center for Education Statistics. (2013b). Digest of educational statistics, 2013 tables and figures. Table 214.40: Public elementary and secondary school enrollment, number of schools, and other selected characteristics, by locale: 2008-09 through 2011-12. Retrieved from www.nces.ed.gov/programs/digest/d13/tables/ dt13_214.40.asp

Utley, C.A., Obiakor, F. E., \& Bakken, J. P. (2011). Culturally responsive practices for culturally and linguistically diverse students with learning disabilities. Learning Disabilities: A Contemporary Journal, 91, 5-18.

Vasquez, E., III, Lopez, A., Straub, C., Powell, S., McKinney, T., Walker, Z., . . . Bedesem, P. L. (2011). Empirical research on ethnic minority students: 19952009. Learning Disabilities Research and Practice, 26(2), 84-93.

Waitoller, F. R., Artiles, A. J., \& Cheney, D. A. (2010). The miner's canary: A review of overrepresentation research and explanations. The Journal of Special Education, 44(1), 29-49. doi:10.1177/0022466908329226

Walker, K. L. (2011). Deficit thinking and the effective teacher. Education and Urban Society, 43(5), 576-597.

Wilkinson, C. Y., Ortiz, A. A., Robertson, P. M., \& Kushner, M. I. (2006). English language learners with reading-related LD: Linking data from multiple sources to make eligibility determinations. Journal of Learning Disabilities, 39(2), 129-141.

Wlodkowski, R. J., \& Ginsberg, M. B. (1995, September). A framework for culturally responsive teaching. Educational Leadership, 53(1), 17-21.

Yin, R. K. (2003). Case study research: Design and methods (3rd ed., Vol. 5). Thousand Oaks, CA: Sage. 


\title{
APPENDIX A
}

\author{
Study Information Letter
}

\section{Dear Colleague,}

There is very little known about the experiences, views, preparation, support and teaching strategies of special education teachers as we find an increasing number of English language learner (ELL) students placed in our classrooms. My study will help find out what training and support we receive and what methods we find effective. I am pursuing this topic as a doctoral student at Portland State University; this study is part of my dissertation. As a peer, I know we have a vast depth of knowledge based on our experiences and it is untapped.

The purpose of this study is to describe special education teachers' experiences teaching students currently or previously enrolled in an English language learner program who are receiving special education services by exploring their views of what supports, resources and strategies contribute to student success and teachers' views of the eligibility determination and referral process.

I hope to a conduct a 60-minute interview at your convenience sometime in June, July or August at a location of your choosing. Field notes will be taken during the interview and at the conclusion, I will summarize my notes and ask you to confirm that they accurately reflect your comments. At this time you can clarify or add further comments. The interview will be recorded digitally on an Ipad and after the interview, all information that could identify you will be deleted and the audio file will be renamed with a code name. The interview will be transcribed verbatim only after all identifying information is deleted and this transcript file will also be given a code name. During the interview you can choose to not to answer any question and/or leave the study at any time.

I am seeking participants who:

- Are currently certified in special education in the state of Oregon.

- Are currently employed as a special education teacher in one of two school districts in Oregon.

- Have three years or more of employment as a special education teacher.

- Have one-year minimum experience serving one or more students with eligibilities for both special education and ELL.

- And/or have one-year minimum experience serving one or more students with a current eligibility for special education who at one time in their K-12 school career had an eligibility for English language services that has since been dropped.

If you have any questions and/or are interested in participating, please contact me at edubois@pdx.edu.

Thank you for your consideration.

Sincerely,

Elizabeth DuBois 


\section{APPENDIX B}

\section{Letter of Informed Consent}

\section{Dear Colleague,}

I appreciate your participation in my study.

The purpose of this study is to describe special education teachers' experiences teaching students currently or previously enrolled in an English language learner program who are receiving special education services by exploring their views of what supports, resources and strategies contribute to student success and teachers' views of the eligibility determination and referral process.

This interview will be record digitally on an Ipad and transcribed verbatim only after all identifying information is deleted. The transcript file will be given a code name to protect your identity. During the interview you can choose to not to answer any question and/or leave the study at any time.

You have met the following criteria:

- Are currently certified in special education in the state of Oregon.

- Are currently employed as a special education teacher in one of two school districts in Oregon.

- Have three years or more of employment as a special education teacher.

- Have one-year minimum experience serving one or more students with eligibilities for both special education and ELL.

- And/or have one-year minimum experience serving one or more students with a current eligibility for special education who at one time in their K-12 school career had an eligibility for English language services that has since been dropped.

I agree to participate and understand I may withdraw at any time.

(Your initials)

I agree to maintain the participants' confidentiality.

(Researchers' signature)

Date 
APPENDIX C

INTERVIEW GUIDE

\begin{tabular}{|c|c|}
\hline Research Questions & Interview Questions \\
\hline $\begin{array}{l}\text { 1. How are special educators } \\
\text { prepared to teach students } \\
\text { currently or previously } \\
\text { enrolled in an English } \\
\text { language learner program } \\
\text { who are receiving special } \\
\text { education services students? }\end{array}$ & $\begin{array}{l}\text { Q1. Have you received training specific to ELL students? } \\
\text { Q2. What form has it taken? } \\
\text { Q3. Have you received Professional Development specifically } \\
\text { addressing needs of dual identified students? }\end{array}$ \\
\hline $\begin{array}{l}\text { 2. What resources are } \\
\text { provided special educators } \\
\text { teaching these students? }\end{array}$ & $\begin{array}{l}\text { Q1. What resources has your special education department provided to } \\
\text { you to serve these students? } \\
\text { Q2. When you have a question or want guidance about teaching ELL } \\
\text { students, to whom do you address it to? }\end{array}$ \\
\hline $\begin{array}{l}\text { 3. What strategies do special } \\
\text { educators find promote } \\
\text { success for these students? }\end{array}$ & $\begin{array}{l}\text { Q1. What strategies do you find promote the success of dual identified } \\
\text { students? } \\
\text { Q2. How did you learn of these strategies? }\end{array}$ \\
\hline $\begin{array}{l}\text { 4. As reported by special } \\
\text { educators, how do special } \\
\text { educators and ELL teachers } \\
\text { collaborate to teach these } \\
\text { students? }\end{array}$ & $\begin{array}{l}\text { Q1. How much time does your student spend receiving ELL services } \\
\text { from ELL teacher? Is that listed on the IEP? } \\
\text { Q1. How much time does the ELL teacher spend in consultation with } \\
\text { you? Is that listed on the IEP? } \\
\text { Q3. What does your collaboration look like with the ELL teacher in } \\
\text { your building? }\end{array}$ \\
\hline $\begin{array}{l}\text { 5. What are special } \\
\text { educator's experiences with } \\
\text { and impressions of the } \\
\text { referral and placement } \\
\text { process of ELL students into } \\
\text { special education? }\end{array}$ & $\begin{array}{l}\text { Q1. I would like you to describe and reflect on your experiences with } \\
\text { the referral and placement process of ELL students into Special } \\
\text { Education. Would you share your impressions? } \\
\text { Q2. What parts of the process worked well? } \\
\text { Q3. What parts of the process can be improved? }\end{array}$ \\
\hline $\begin{array}{l}\text { 6. What do special educators } \\
\text { think about the idea that there } \\
\text { is a disproportionate number } \\
\text { of ELL students referred to } \\
\text { special education? }\end{array}$ & $\begin{array}{l}\text { Q1. Are you aware of the disproportionate number of ELL students } \\
\text { referred to special education? } \\
\text { Q2. What do you think this might be attributed to? }\end{array}$ \\
\hline
\end{tabular}




\section{APPENDIX D}

\section{A Self-Study Guide for Reflecting on Anti-Bias Curriculum Planning and Implementation}

A. Raising self-awareness:

1. Am I aware of my own cultural identity and history? How comfortable am I about who I am?

2. Am I aware about any biases I have?

3. Do I view diversity and exceptionalities as strengths and that all children can succeed?

4. a. Am I able to give accurate, honest answers to children's questions about differences?

b. Am I comfortable admitting when I do not know the answer to a question?

5. a. Am I able to intervene with ease when I hear comments that exclude someone, show bias, or are discriminatory?

b. Do I model ways for responding to bias?

6. Do I have access to colleagues who can act as a trusted ally in my diversity and anti-bias work, offering support ad challenges to my thinking and actions?

B. The physical environment:

1. Are the materials and equipment in my classroom easily accessible ti o all?

2. Do all children have equal opportunity to participate in activities?

3. Does my classroom display pictures of the children, their families and include materials that relate to their background and experience (i.e., pictures of familiar places)?

4. Does my classroom provide equal representation of images and materials reflecting:

a. Different cultures and ethnicities?

b. Different family styles and compositions?

c. Different age groups across different lifestyles?

d. Different genders in non-stereotypical roles?

5. Are their dolls and clothing that represent male/female and different ethnicities/skin colors?

6. Is there a wide variety of art media that students can se to accurately represent their physical characteristics?

C. The pedagogical environment:

1. Are my verbal and non-verbal messages free of stereotypes and hidden bias?

a. Do I effectively provide opportunities for students to value and explore diversity in themselves and others?

b. Are the colors black and brown equally valued as other colors in my classroom? 
c. Do I actively encourage critical thinking about differences, stereotypes and biases?

d. Do I teach about minority and non-minority groups who have devoted their lives to ending injustice?

2. Do I equally respect and acknowledge all children on their efforts and accomplishments?

3. Do I hold and convey high expectations for learning for all students?

4. Do I see and treat each child as an individual and as a member of different social and cultural groups?

5. In my communications and curriculum, do I recognize that children may be cared for by various family members and/or have differing family compositions?

6. Do I recognize and respect children's individual and culturally based learning styles:

a. Do I effectively differentiate instruction to reach diverse learning styles?

b. Do I integrate multiple methods of communication to support children's learning (visual, auditory,...)?

c. Do I use a variety of methods to evaluate children's learning?

7. Do I promote cooperation between and among children from diverse groups through curriculum and classroom routines?

8. Do I help children critically think about and problem solve fairness issues in daily classroom activities and routines?

D. Relationships with families an community:

1. Do I initiate conversations in a culturally responsive way with all families?

2. Do I provide the option for providing translations of newsletters and at meetings for families who do not speak English?

3. When food is provided at classroom functions, is it food that is reflective of the community/families?

4. Do I support different transitions and care-giving routines while being aware of school/center policies, responding to families requests respectfully and fairly, and genuinely work to negotiate an agreement when there is a conflict about childcare beliefs and goals?

5. Do I truly welcome family participation in my classroom? If they are unable to come in, do I encourage it in other ways?

6. Do I include families in creating the learning environment for children?

7. Do I know enough about the local community to extend children's learning beyond the classroom walls?

8. Am I able to effectively use resources and other adults in the community to enhance children's learning about diversity and bias? 
Source: Chen, D. W., Nimmo, J., \& Fraser, H. (2009). Becoming culturally responsive early childhood educator: A tool to support reflection by teachers embarking on the anti-bias journey. Multicultural Perspectives, 11(2), 101-106. 


\title{
APPENDIX E
}

\section{Culturally Responsive Referral Guide}

\author{
Student: \\ Referred by: \\ Primary Area of Concern: \\ Bilingual: Y N \\ Reason for Referral (one sentence): \\ Referral Body of Evidence: Provide referral material relative to each \\ cultural/linguistic item in the same class/grade
}

Cultural/Linguistic item

1. Minimum of eight data points showing that the ELL student is functioning below benchmark for age/grade/language proficiency

(i.e. assessment scores relative to their peers)

2. Justification statement (one-two paragraphs) describing the academic behaviors of the ELL student specifically indicating why this learner is being submitted for referral over other ELL students receiving similar specific skill instruction in same class/grade

3. Confirmation statement indicating that English language development (ELD) is provided by/or in collaboration with an educator(s) with formal training and experience in teaching ELD

4. Statement describing how native language and English are used in the acquisition of content and skills as well as the acquisition of English

5. Evidence confirming that Tier 1 instruction is implemented consistently and accurately in content area of need, including use of the appropriate accommodations for teaching ELL students (i.e. culturally responsive)

6. Statement (1-2 paragraphs) or other documented evidence describing Tier 2 supports and intervention(s) used to appropriately meet ELL students needs in the content area of concern

7. Evidence (2-3 pieces) of class performance showing that problem exists when using both native and English languages in classroom and school activities
Source/Reporting Entity*

Progress monitoring scores/ Referring Team

Classroom evidence/ Referring Teacher

Teacher Records/

Building Principal

Coaching Activities/

Coach or Referring Teach

Coaching activities, appropriate assessment/ Coach or Master Teacher

Tier 2 intervention plan/ Referring Team

Student work, Observations/ Referring Teacher, ELL Teacher 
8. Evidence that multiple sources are used to document ELL student's academic and language progress including family/home

Referring Team, School Psych

9. Statement indicating the ELL students appears to have at least two characteristics (based on instructional evidence) typically associated with a learning disability (short term memory, social skills, disorganization, trouble working independently or maintaining self-regulatory behaviors)

10. Evidence that learning characteristics discussed in Item 9 appear during instruction delivered in both native and English languages, if bilingual
Progress monitoring data, Interviews, Student work/
Classroom Observations, District Checklist/

School Psych

* Recommended educator to gather item material is indicated in italics in right column

Source: Hoover, J. J., \& Erickson, J. (2015). Culturally responsive special education referrals of english language learners in one rural county school district: Pilot project. Rural Special Education Quarterly, 34(4), 18-28. 